\title{
Lateral Intermolecular Electronic Interactions of Diketopyrrolopyrrole $D-\pi-A$ Solar Dye Sensitizers Adsorbed on Mesoporous Alumina
}

\author{
Hee-Won Bahng, ${ }^{\dagger, \S}$ Anders Hagfeldt, ${ }^{\ddagger, \S}$ and Jacques-E. Moser* ${ }^{*} \dagger, \S \odot$ \\ ${ }^{\dagger}$ Photochemical Dynamics Group, Institute of Chemical Sciences \& Engineering, ${ }^{\dagger}$ Laboratory of Photomolecular Science, Institute \\ of Chemical Sciences \& Engineering, and ${ }^{\S}$ Lausanne Centre for Ultrafast Science (LACUS), École polytechnique fédérale de \\ Lausanne, 1015 Lausanne, Switzerland
}

\section{Supporting Information}

ABSTRACT: The development of push-pull organic dyes utilizing the donor- $(\pi$ conjugated bridge)-acceptor $(\mathrm{D}-\pi-\mathrm{A})$ motif has induced a paradigm shift in the design of efficient nanocrystalline dye-sensitized solar cells (DSSCs), offering control over the aesthetic properties and performance. Because of the large transient dipole moment characterizing this type of dye upon photoexcitation, these molecules are intrinsically subjected to significant lateral electronic interactions once adsorbed on a solid surface, which can greatly affect the efficiency of the electron injection in DSSCs. Here, we investigated the detailed intermolecular interactions upon photoexcitation of $\mathrm{D}-\pi-\mathrm{A}$ diketopyrrolopyrrole (DPP)-based dye molecules, denoted (E)-3-(5-(4-(4(5-(4-(bis $\left(2^{\prime}, 4^{\prime}\right.$-dibutoxy-[1,1'-biphenyl]-4-yl)amino)phenyl)thiophen-2-yl)-2,5-bis(2-ethylhexyl)-3,6-dioxo-2,3,5,6-tetrahydropyrrolo[3,4-c]pyrrol-1-yl)phenyl)furan-2yl)-2-cyanoacrylic acid (DPP_A) and commercially available under the name "Dyenamo Blue", using ultrafast transient absorption spectroscopy. A comparison of the excited-state properties of the molecule with those of a similar dye lacking the triarylamine donor moiety (DPP_R) revealed the critical role played by the donor in determining the mechanisms of intermolecular interactions. The results showed that the intermolecular interactions between DPP_A molecules in solution caused partial delocalization of excitons in a process involving the participation of the triarylamine moiety. Lateral charge transfer (CT) between DPP_A molecules adsorbed on the redox-inactive surface of $\mathrm{Al}_{2} \mathrm{O}_{3}$ was observed upon photoexcitation and yielded CT excitons between neighboring dyes. Furthermore, on the basis of the experimental evidence obtained from the pump fluence-dependent transient absorption and excitation spectra, the DPP_R molecules adsorbed on the $\mathrm{Al}_{2} \mathrm{O}_{3}$ film exhibited intermolecular $\pi-\pi$ interactions, inducing the formation of excimer-like excited states. These results suggest that lateral intermolecular electronic interactions between dye sensitizer molecules adsorbed on the surface of a semiconductor can have a strong influence on the dynamics of electron injection in DSSCs and should thus be considered in the molecular design of new efficient dyes.

\section{INTRODUCTION}

An important area of research is currently devoted to the development of metal-free dyes for the preparation of dyesensitized solar cells (DSSCs) with high power conversion efficiencies. $^{1-3}$ Organic dye sensitizers possess many advantages, such as high extinction coefficients, low cost, and good tunability of the highest occupied molecular orbital and lowest unoccupied molecular orbital orbital energy levels. ${ }^{4}$ In particular, easy tuning of their absorption spectra can be conducted through modification of the molecular design by introducing different light-absorbing moieties. ${ }^{5}$ These dye sensitizers are then used in molecular frameworks that typically consist of donor $-(\pi$-conjugated bridge $)$-acceptor $(D-\pi-A)$ systems. ${ }^{6,7} \mathrm{D}-\pi-\mathrm{A}$ systems are associated with efficient intramolecular charge transfer (CT) from the donor to the acceptor during photoexcitation, and transient kinetic studies have been conducted by varying the donor or acceptor moieties in an attempt to correlate the kinetics with the device performance. $^{8-10}$ Despite the vast amount of research on and general understanding of the $\mathrm{D}-\pi-\mathrm{A}$ system in the context of solar cells, the intermolecular interactions formed between dyes are not yet fully understood. The intermolecular electronic interactions formed between adsorbed dyes on the surface of a solid oxide film are crucial in the electron transfer processes of DSSCs because these interactions can facilitate various processes, such as reductive quenching ${ }^{11,12}$ or dye aggregate formation, ${ }^{13-15}$ that can affect the kinetics and efficiency of interfacial CT upon photoexcitation.

Because the organic dyes in solar cell devices are tightly packed on the metal oxide surface, in order to comprehensively understand a $\mathrm{D}-\pi-\mathrm{A}$ system, it is important to not only investigate the kinetic traces of the interfacial dynamics but

Received: May 21, 2018

Revised: July 28, 2018

Published: August 8, 2018 
also the lateral interactions arising from the short intermolecular distance. A recent attempt to investigate the latter can be found in ref 16 . The work in that report is focused mainly on the charge separation product of the intermolecular interactions occurring upon photoexcitation of organic dyes adsorbed on inert $\mathrm{Al}_{2} \mathrm{O}_{3}$ films. ${ }^{16}$ Unfortunately, that study did not consider the role of the donor, which is essential for understanding the intermolecular interactions, as the presence of the donor is strongly related to the formation of an exciton that participates in the interaction, as we will show. Thus, to fully understand the $\mathrm{D}-\pi-\mathrm{A}$ characteristics of organic sensitizers, further investigation is needed to explore the structural effect on intermolecular photodynamics.

The promotion of lateral hole transfer by the triphenylamine (TPA) electron donating group comprised in particular heteroleptic $\mathrm{Ru}(\mathrm{II})$ polypyridyl complex sensitizers adsorbed on the surface of solid oxides has been recently reviewed. The kinetic interplay between intermolecular and intramolecular electron transfer in $\mathrm{TPA}-\pi$ bridge- $\mathrm{Ru}(\mathrm{II})$ dye sensitizers adsorbed on $\mathrm{TiO}_{2}$ was also discussed in detail. ${ }^{17}$

In the present work, to investigate the $\mathrm{D}-\pi-\mathrm{A}$ characteristics, we examine the detailed dynamics of an important D- $\pi$-A sensitizer, (E)-3-(5-(4-(4-(5-(4-(bis $\left(2^{\prime}, 4^{\prime}\right.$-dibutoxy[1,1'-biphenyl]-4-yl)amino)phenyl)thiophen-2-yl)-2,5-bis (2ethylhexyl)-3,6-dioxo-2,3,5,6-tetrahydropyrrolo[3,4-c]pyrrol-1yl)phenyl)furan-2-yl)-2-cyanoacrylic acid (DPP_A), by comparing its characteristics with a similar molecule lacking the donor moiety (DPP_R) both in solution and adsorbed on a redox-inactive alumina substrate (Figure 1). DPP_A is an
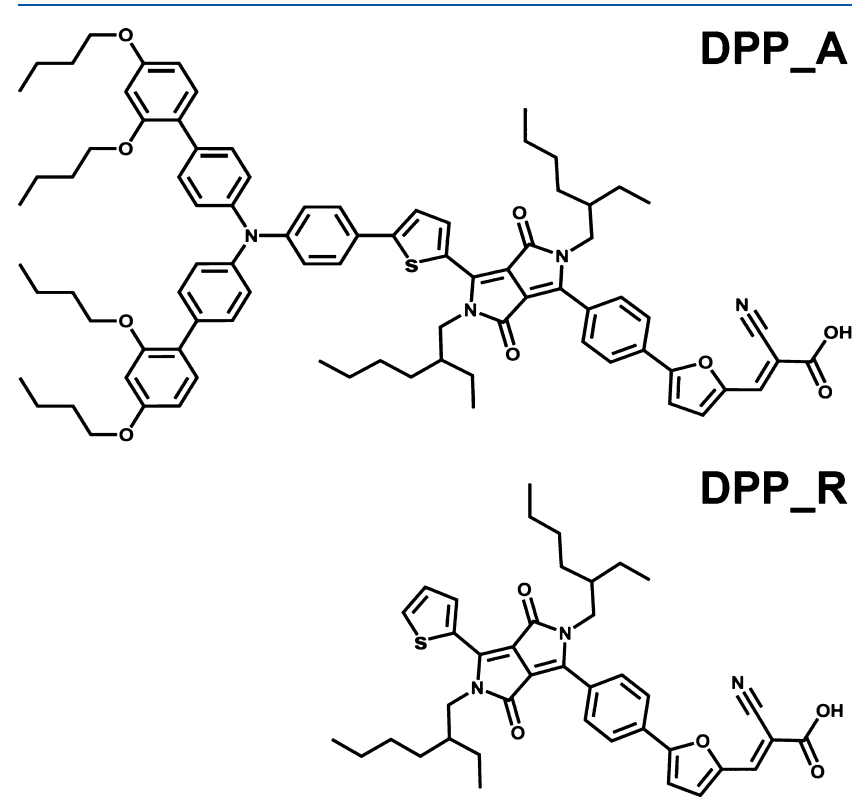

Figure 1. Molecular structures of dyes DPP_A and DPP_R.

interesting dye for use in DSSCs because of its combination of an aesthetically attractive blue color and ability to efficiently harvest the red and near-infrared (NIR) parts of the incident solar spectrum. ${ }^{18}$

To observe the characteristics of the intermolecular interactions, we performed steady-state and femtosecond transient absorption spectroscopy (fs-TAS) measurements in solution and on inert $\mathrm{Al}_{2} \mathrm{O}_{3}$ films with varying dye concentrations. From the experimental results, we observe that in the solution phase, partially delocalized excitons participate in the intermolecular interactions of DPP A because of the presence of the TPA donor. We also find that when the dyes are adsorbed on the $\mathrm{Al}_{2} \mathrm{O}_{3}$ surface, the lateral intermolecular interactions upon photoexcitation are accelerated in DPP A because of the formation of CT excitons between neighboring dye molecules. On the other hand, the solution-phase donorless DPP_R dye does not display the participation of partially delocalized excitons in the intermolecular interactions, unlike DPP_A. Another very important observation is that on the basis of experimental evidence from the pump fluence-dependent transient absorption (TA) and excitation spectra, an excimer-like excited state is involved in the lateral intermolecular interactions between DPP_R dye molecules adsorbed on the film. On the basis of thorough investigation, we argue that the type of exciton that forms and participates in lateral interactions on the film is determined by the presence of the bulky donor group. This result sheds light on another function of the $\mathrm{D}-\pi-\mathrm{A}$ structure as a photosensitizer because the characteristics of the exciton not only has an impact on the efficiency of the lateral intermolecular interactions but can also affect the CT mechanism that determines the photovoltaic performance of DSSCs. The influence of the intermolecular interactions on the CT mechanism in DSSC devices will be investigated as a next step in our follow-up work. ${ }^{19}$

\section{METHODS}

2.1. Sample Preparation. 2.1.1. Solution Samples. The DPP A ("Dyenamo Blue") used in the study was purchased from Dyenamo (Stockholm, Sweden). DPP_R was synthesized according to the procedure detailed in the Supporting Information (S1). DPP $\mathbf{A}$ and DPP $\mathbf{R}$ were dissolved in a 4tert-butanol/acetonitrile mixture $(1: 1 \mathrm{v} / \mathrm{v})^{18}$ and 4-tertbutanol, respectively.

2.1.2. Film Samples. We used homemade $\mathrm{Al}_{2} \mathrm{O}_{3}$ prepared by following the previously reported method ${ }^{20,21}$ and commercial $\mathrm{TiO}_{2}$ (Greatcell Solar, Queanbeyan, Australia) pastes as mesoporous substrates. The average diameters of the $\mathrm{Al}_{2} \mathrm{O}_{3}$ and $\mathrm{TiO}_{2}$ nanoparticles were, respectively, 20 and 18 $\mathrm{nm}$, yielding porosities of 0.67 and 0.625 . Films for spectroscopic experiments were made using fluorine-doped tin oxide (FTO)-coated glass substrates (Tec15, Pilkington). The thickness of the metal oxide films, prepared by screen printing on FTO-coated glass, was controlled at $\sim 4.5 \mu \mathrm{m}$. These films were sintered for $30 \mathrm{~min}$ at $450{ }^{\circ} \mathrm{C}$ before being dipped into a $50 \mu \mathrm{M}$ solution of dye and were kept for less than $3 \mathrm{~h}$ at room temperature. A coadsorbant, chenodeoxycholic acid (CDCA, Sigma-Aldrich), was also dissolved in the dye solution to control the average intermolecular distance when needed. ${ }^{22}$

The surface concentrations of the adsorbed dyes were determined by measuring the absorbance of solutions containing the dyes desorbed from $\mathrm{Al}_{2} \mathrm{O}_{3}$ by dipping the dyed films into a solution of the organic base 1,8diazabicyclo(5.4.0) undec-7-ene.

2.2. Steady-State Measurements. Steady-state absorption spectra were obtained by using a UV-vis spectrophotometer (Varian, Cary 1E), and fluorescence spectra were obtained by using a spectrofluorometer (PerkinElmer, LS 50).

2.3. Femtosecond Transient Absorption Spectroscopy. To record the TA spectra, a fs-TA spectrometer based on a $\mathrm{Ti}$ /sapphire chirped-pulse amplifier system (Clark-MXR, CPA2001) was used. The laser provided pulses at a fundamental 

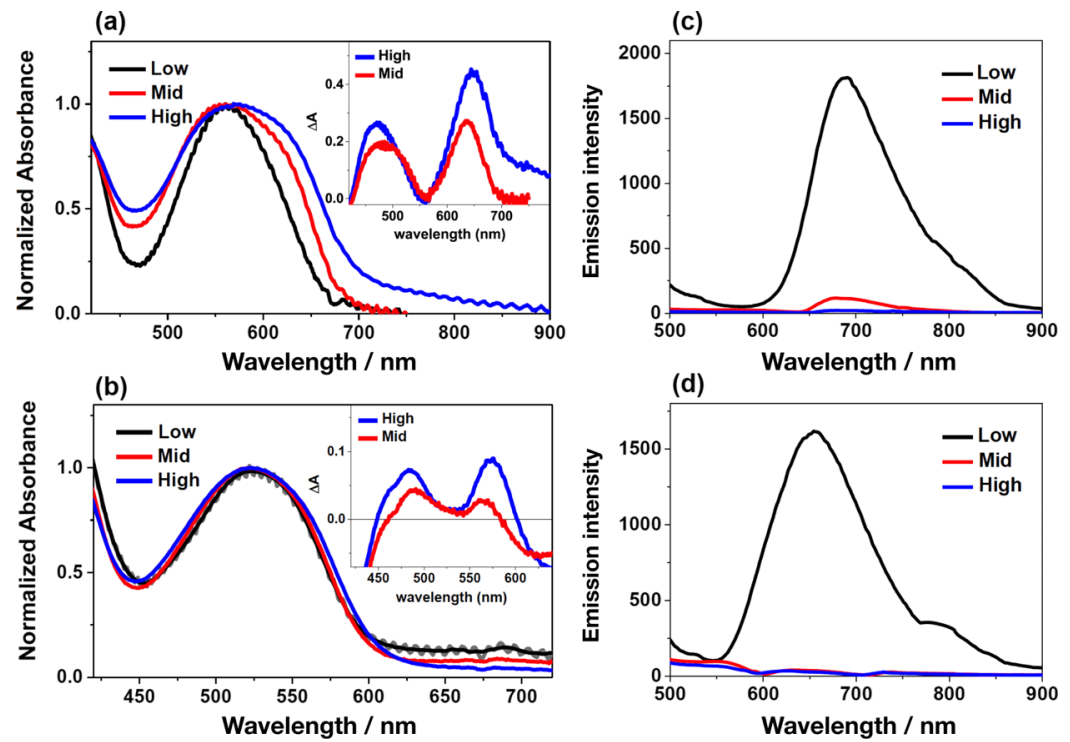

Figure 2. Normalized steady-state absorption spectra of DPP_A (a) and DPP_R (b) dyes adsorbed on mesoporous $\mathrm{Al}_{2} \mathrm{O}_{3}$ at various surface concentrations. Concentrations of CDCA 100 and 50 times larger than those of the dyes were added to the dye solution to prepare the "low" and "mid" film samples, respectively. In the case of the "high" film, no CDCA was added to the dye solution. The fluorescence spectra of DPP_A (c) and DPP_R (d) on $\mathrm{Al}_{2} \mathrm{O}_{3}$ with different dye concentrations were normalized to the fraction of absorbed photons at the excitation wavelength $(390$ $\mathrm{nm}$ ). Insets: Additional absorption transitions appearing in the "mid" and "high" films obtained by subtracting the "low" spectrum from the "mid" and "high" spectra.

Table 1. Steady-State Photophysical Parameters and Concentrations of DPP_A and DPP_R Loaded on $\mathrm{Al}_{2} \mathrm{O}_{3}{ }^{a}$

\begin{tabular}{|c|c|c|c|c|c|c|}
\hline & \multicolumn{3}{|c|}{ DPP_A } & \multicolumn{3}{|c|}{ DPP_R } \\
\hline & low & mid & high & low & mid & high \\
\hline concentration ratio (dye/CDCA) & $1: 100$ & $1: 50$ & $1: 0$ & $1: 100$ & $1: 50$ & 1:0 \\
\hline$c\left(\mu \mathrm{M} / \mathrm{cm}^{2}\right)^{a}$ & 3.89 & 9.19 & 16.94 & 6.51 & 13.19 & 31.05 \\
\hline$\Gamma\left(\times 10^{-25} \mathrm{~mol} / \mathrm{nm}^{2}\right)^{a}$ & 1.33 & 3.33 & 6.16 & 2.32 & 4.83 & 11.3 \\
\hline$d(\mathrm{~nm})^{a}$ & 3.54 & 2.24 & 1.64 & 2.67 & 1.86 & 1.21 \\
\hline$A_{\max }(\mathrm{nm})$ & 562 & 565 & 572 & 522 & 522 & 523 \\
\hline$A_{\max }$ & 0.15 & 0.27 & 0.49 & 0.17 & 0.33 & 0.63 \\
\hline $\mathrm{Fl}_{\max }(\mathrm{nm})$ & 691 & 697 & 719 & 654 & 639 & 636 \\
\hline Stokes shift $\left(\mathrm{cm}^{-1}\right)$ & 3322 & 3352 & 3574 & 3867 & 3508 & 3397 \\
\hline Davydov splitting $(\mathrm{eV})$ & & 0.62 & 0.71 & & 0.37 & 0.42 \\
\hline
\end{tabular}

${ }^{a} c$ represents the geometrical concentration of the dye on the $\mathrm{Al}_{2} \mathrm{O}_{3}$ porous layer. The dye coverage on the surface, $\Gamma$, and the intermolecular distance $d$ between dye molecules are derived from $c$ (see the Supporting Information, Table S1).

wavelength of $778 \mathrm{~nm}$ with a $1 \mathrm{kHz}$ repetition rate and a $150 \mathrm{fs}$ pulse duration. The laser output was split and used for two purposes: as the pump after performing frequency doubling through a nonlinear beta-barium borate crystal $(389 \mathrm{~nm})$ and as the probe beam by sending it to a sapphire plate to produce a broadband white light continuum $(420-770 \mathrm{~nm})$. The time delay between the pump and probe beams was carefully controlled by making the pump beam travel along a variable optical delay with the use of a motorized translation stage (Physik Instrumente, M531 PD). To obtain the time-resolved transient absorbance difference signal $(\Delta A)$ at a specific time, the pump pulses were chopped at $500 \mathrm{~Hz}$, and absorption spectra intensities were alternatingly saved with and without the pump pulse. The probe beam was detected shot by shot with two spectrographs (Andor Technology) equipped with $512 \times 58$ pixel back-thinned CCD cameras (Hamamatsu S07030-0906). A satisfactory signal-to-noise ratio was obtained by averaging over 2500 shots. The polarization angle between the pump and the probe beams was set to the magic angle $\left(54.7^{\circ}\right)$ using a Glan-laser polarizer with a half-wave retarder to prevent polarization-dependent signals. A $500 \mu \mathrm{J} / \mathrm{cm}^{2}$ pump energy fluence was used on the solution samples, and the energy fluences on the film samples were limited to a maximum of $160 \mu \mathrm{J} / \mathrm{cm}^{2}$. White light chirp correction was conducted by the Kerr grating technique.

\section{RESULTS}

3.1. Steady-State Absorption and Fluorescence Spectra. Figure 2 presents the stationary absorption and fluorescence spectra of the DPP A and DPP $\mathbf{R}$ dyes loaded on $\mathrm{Al}_{2} \mathrm{O}_{3}$ films with different concentrations. The amount of adsorbed dye was controlled by changing the ratio of CDCA to dye in the dye solution. Sintered $\mathrm{Al}_{2} \mathrm{O}_{3}$ films were dipped into solutions having dye to CDCA ratios of 1:100, 1:50, and 1:0, and the resulting samples are denoted "low", "mid", and "high", respectively, in which the label refers to the surface concentration of dye. As listed in Table 1, the calculated dye concentration is enhanced when the ratio of CDCA to dye decreases. 

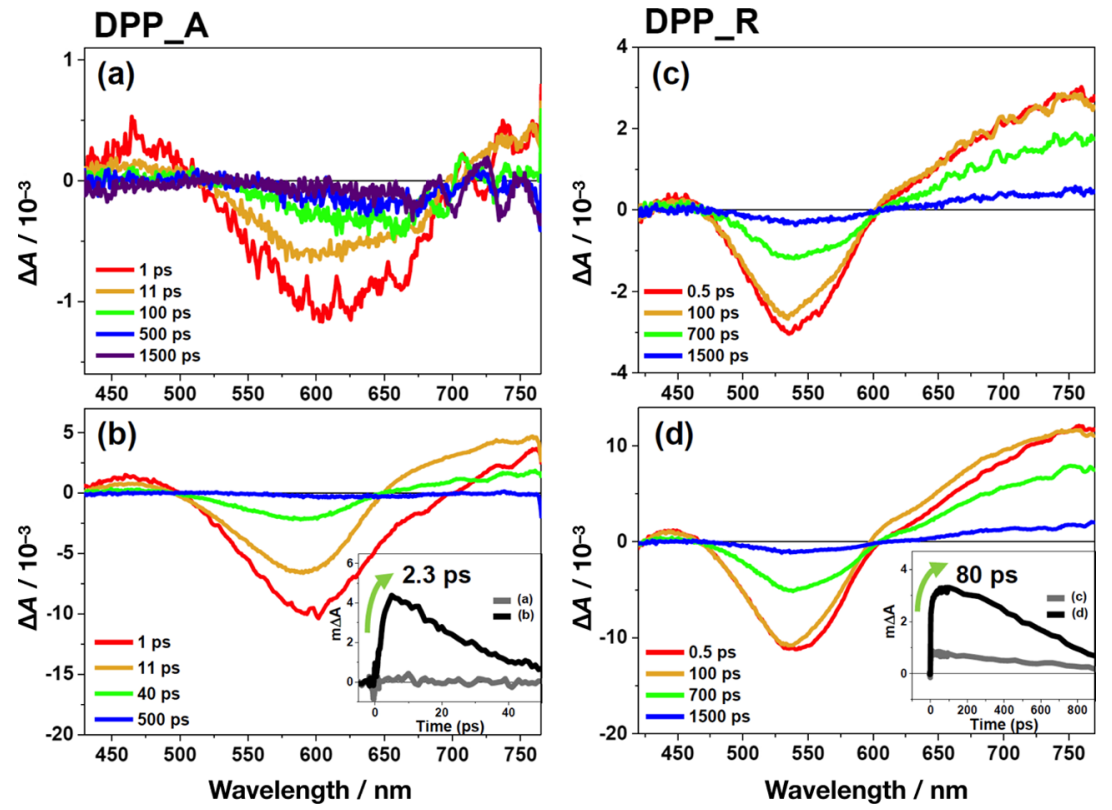

Figure 3. TA spectra of DPP_A (a,b) and DPP_R (c,d) at different optical delays in a 4-tert-butanol/acetonitrile mixture (1:1 v/v) and 4-tertbutanol, respectively. Each dye was dissolved in solvent at different concentrations. The concentrations of the solutions are $15 \mu \mathrm{M}(\mathrm{a})$ and $130 \mu \mathrm{M}$ (b) for DPP_A and $24 \mu \mathrm{M}$ (c) and $140 \mu \mathrm{M}$ (d) for DPP_R. In the measurement, $390 \mathrm{~nm}$ light was used as the pump source, and the energy

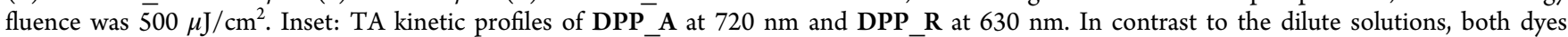
exhibit clear rising components in the concentrated solutions.

The average distance between neighboring DPP A dye molecules was derived by dividing the dye concentration by the specific surface area of the $\mathrm{Al}_{2} \mathrm{O}_{3}$ nanoparticles constituting the oxide film. The specific surface area was measured by Brunauer-Emmett-Teller analysis, and the detailed calculation procedure is described in the Supporting Information (S2). For example, in the case of the "high" DPP A film, the area covered by a single molecule on the surface was calculated to be $2.69 \mathrm{~nm}^{2}$, corresponding to an intermolecular distance of $1.64 \mathrm{~nm}$. The intermolecular distances of all cases are listed in Table 1.

As shown in Figure 1a,b, the absorbance of DPP_A is redshifted compared to that of DPP_R, corresponding to a 0.17 $\mathrm{eV}$ reduction in the excitation energy. This red shift can clearly be attributed to the enhanced transition dipole moment of DPP_A induced by the inclusion of the TPA group on the DPP core, which increases the effective $\pi$-conjugation length in DPP_A. Upon increasing the loaded dye concentration, small bathochromic shifts are observed in the absorption spectra of DPP_A, whereas DPP_R does not display any spectral shifts. The absorption spectrum of the concentrated dye film is broader for DPP_A, showing the occurrence of additional transitions on each side of the band at $572 \mathrm{~nm}$, and the intensities of these additional bands are weak in the case of the "high" DPP_R film compared to those of the corresponding DPP_A film. The occurrence of additional bands in the absorption spectra of the "mid" and "high" films is observed, as shown in the inset of Figure 2.

The emergence of the two additional bands may arise from exciton splitting because of electronic coupling between neighboring dyes, which allows $\mathrm{H}$ - and J-type optical transitions that arise from face-to-face and head-to-tail molecular stacking orientations, respectively. ${ }^{23,24}$ Indeed, the change in the energy difference between the high-energy $\mathrm{H}$ band and the low-energy J-band, corresponding to Davydov splitting (DS $)^{25}$ with the increasing dye concentration confirms the occurrence of exciton splitting. As listed in Table 1, the DS values are positively correlated with the magnitude of the transition dipole moment and negatively correlated with the intermolecular distance. ${ }^{26}$ Moreover, the DS values of DPP_R are 0.37 and $0.42 \mathrm{eV}$, which are in the range of the DS values for other similar molecular structures reported in an experimental study. ${ }^{23}$

The fluorescence spectra of the DPP_A and DPP_R films are displayed in Figure $2 \mathrm{c}$,d. Significant quenching is observed as the dye concentration increases when the fluorescence intensities are normalized to the fraction of absorbed photons at the excitation wavelength. Because the energy level of the $\mathrm{Al}_{2} \mathrm{O}_{3}$ conduction band edge is too high, electrons cannot be injected from the excited dye into the solid, meaning that lateral intermolecular interactions rather than interfacial electron transfer are responsible for the observed quenching. $^{27-29}$

3.2. Time-Resolved Transient Absorption Spectroscopy. 3.2.1. Solution Studies. Figure 3 shows the fs-TA spectra of DPP_A and DPP_R solutions with various dye concentrations in the UV-visible to NIR region (420-770 $\mathrm{nm})$. Concentrations of 15 and $130 \mu \mathrm{M}$ for DPP A and 24 and $140 \mu \mathrm{M}$ for DPP $\mathbf{R}$ were used to observe the intermolecular behaviors in the solution phase. Both the dilute (a) and concentrated (b) DPP_A solutions show ground-state bleaching (GSB) with peaks at ca. $600 \mathrm{~nm}$, which overlap with the ground-state absorption spectra when inverted, suggesting the occurrence of an $S_{0} \rightarrow S_{1}$ transition. Additionally, excitedstate absorptions (ESAs) are superimposed on each side of the GSB bands, which are important when analyzing the intermolecular interaction, as will be discussed later. DPP $\mathbf{R}$ (Figure 3c,d) exhibits similar behaviors as DPP_A, such as the generation of GSB bands with peaks at ca. $530 \mathrm{~nm}$, and these GSB bands are again mixed with ESA bands on each side. The 

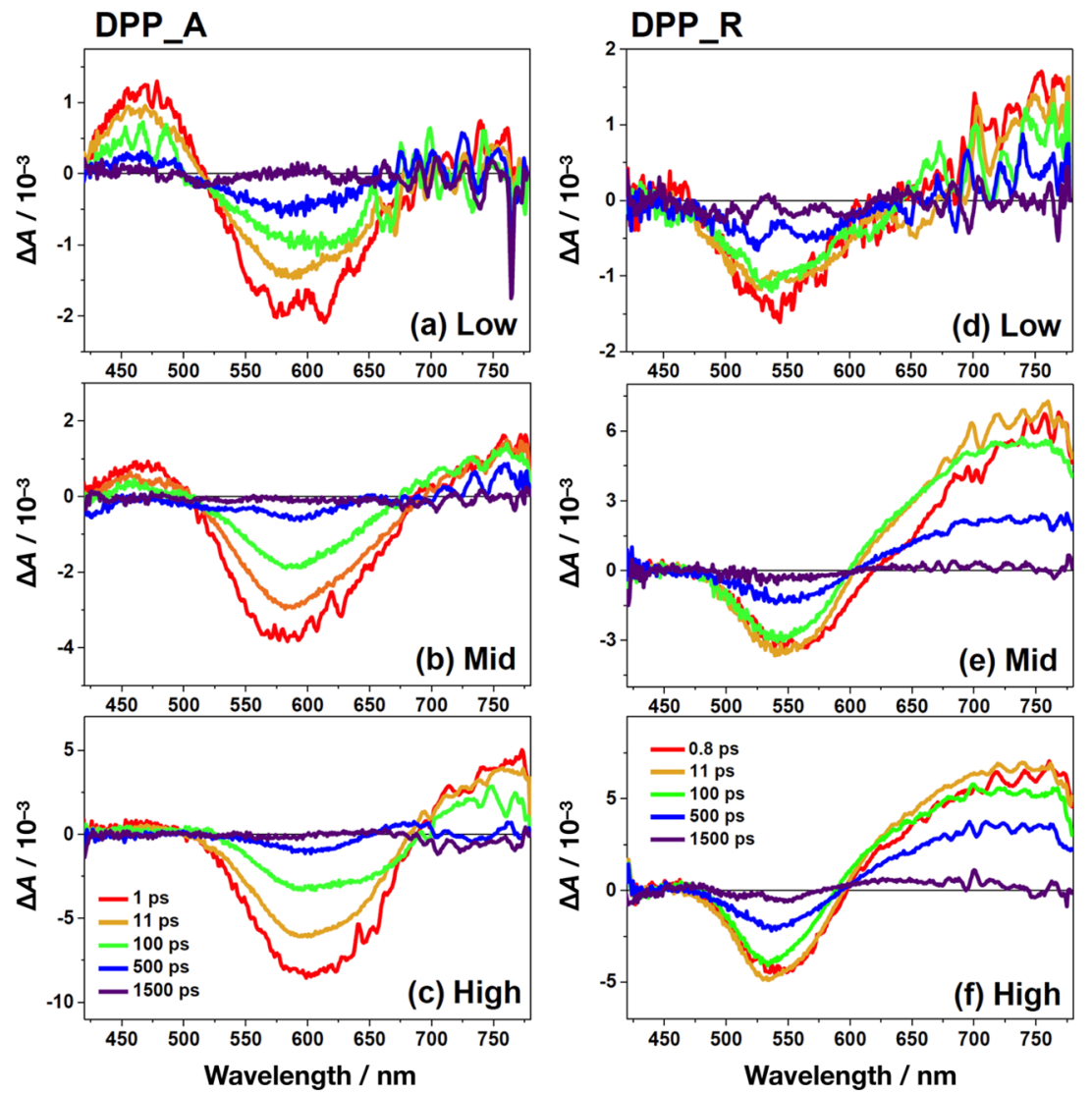

Figure 4. TA spectra of DPP_A (a-c) and DPP_R (d-f) on $\mathrm{Al}_{2} \mathrm{O}_{3}$ at different optical delays. "low" (dye/CDCA = 1:100), "mid" (dye/CDCA = 1:50), and "high" (dye $/ \mathrm{CDCA}=1: 0)$ films were excited at $390 \mathrm{~nm}$ with $28 \mu \mathrm{J} / \mathrm{cm}^{2}$.

DPP R spectra are similar for both dye concentrations. While the spectral features of DPP_A are sensitive to the dye concentration, they show an undefined isosbestic point when mixed with the red-side ESA band in the high-concentration solution. Intermolecular interactions are observed in the highconcentration solution at wavelengths corresponding to the formation of new excited-state bands in the TA kinetic profiles, which clearly show the growth of new components compared to the dilute solutions.

In the highly concentrated solution, the average multiexponential fits to the transients of DPP A and DPP $\mathbf{R}$ provide rising components of 2.3 and $80-\mathrm{ps}$, respectively, followed by 25 and 580 ps decay components (Supporting Information, Table S2). The reduction in the fitted time components of DPP_A can be explained by the enhanced intramolecular CT characteristic of the excited state, which comes from the strongly electron donating TPA moiety. ${ }^{23}$ Moreover, the bulky donor group, which introduces flexibility in the overall molecular structure in the solution phase, opens up new deactivation channels, ultimately accelerating the decay processes. $^{30}$

3.2.2. Alumina Film Studies. Figure 4 shows selected TA spectra from the investigation of the fs dynamics of DPP_A and DPP_R adsorbed on $\mathrm{Al}_{2} \mathrm{O}_{3}$ with different CDCA ratios. From "low" to "high", additional positive bands are formed above $700 \mathrm{~nm}$ in DPP_A and at ca. $630 \mathrm{~nm}$ in DPP_R.

In DPP_A, the intensity ratio of the new absorption $\bar{b}$ and to the GSB band at $580 \mathrm{~nm}, I_{710 \mathrm{~nm}} / I_{580 \mathrm{~nm}}$, increases from 0.10 to 0.15 and 0.36 as the concentration increases. This trend is also valid for DPP_R, whose intensity ratio of the new absorption band to the GSB band, $I_{630 \mathrm{~nm}} / I_{530 \mathrm{~nm}}$, changes from 0 to 0.71 and 0.74 . These representative wavelengths of DPP_A (710 $\mathrm{nm})$ and DPP_R $(630 \mathrm{~nm})$ were chosen to minimize the disturbance by the excited-state relaxations. The sensitivity of these bands to the dye concentration reveals that lateral intermolecular interactions, which are accelerated by the short intermolecular distances, are responsible for the new bands. ${ }^{16}$

The conversion into new states disturbs the excited-state relaxations, as shown by the quenching of the intrinsic excited states, which is specifically observed at band intensities below $510 \mathrm{~nm}$ for DPP_A and above $670 \mathrm{~nm}$ for DPP $\mathbf{R}^{31-33}$ At a representative wavelength of $470 \mathrm{~nm}$, which is related to the excited-state relaxation of DPP_A, the absorption ratio $I_{470 \mathrm{~nm}} /$ $I_{580 \mathrm{~nm}}$ changes from 0.47 to $0 . \overline{2} 3$ and 0.11 in the order from "low" to "high". This trend demonstrates that 51 and $77 \%$ of the DPP_A molecules are quenched in the "mid" and "high" films, respectively.

In the case of DPP_R, the quenching proportions cannot be directly derived as they were in the case of DPP_A because all the excited-state relaxation bands are superimposed with the lateral intermolecular interaction bands in the observable spectral region $(650-770 \mathrm{~nm})$. More specifically, the changes in the absorption values above $650 \mathrm{~nm}$ are determined by the influential process from two origins. For example, the $I_{760 \mathrm{~nm}} /$ $I_{530 \mathrm{~nm}}$ value changes from 0.89 to 2.03 and 1.38 in the order from "low" to "high". The increase in the value from "low" to "mid" indicates that the lateral intermolecular interactions have a stronger effect on the emergence of the new band in this step than excited-state quenching, while the decrease in value from "mid" to "high" reflects the opposite relationship. This result 
(a) DPP_A

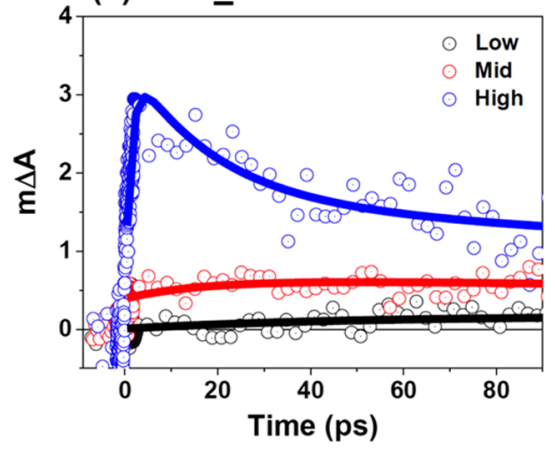

(b) DPP_R

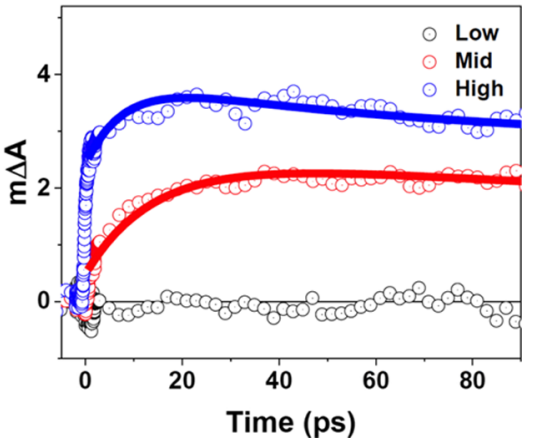

Figure 5. TA kinetic profiles of DPP_A (a) and DPP_R (b) on $\mathrm{Al}_{2} \mathrm{O}_{3}$ observed at 710 and $630 \mathrm{~nm}$, respectively. All films were excited at $390 \mathrm{~nm}$ with $28 \mu \mathrm{J} / \mathrm{cm}^{2}$.

means that the lateral intermolecular interactions between DPP $\mathbf{R}$ dye molecules reach saturation in the "mid" film, which is in line with many other observations. Specifically, the "mid" and "high" films show similar fluorescence intensities, TA intensity ratios $\left(I_{630 \mathrm{~nm}} / I_{\mathrm{GSB}}\right)$, and rising time components in the TA kinetics.

Figure 5 shows the kinetic traces at representative wavelengths reflecting the lateral intermolecular interactions in DPP A $(710 \mathrm{~nm})$ and DPP $\mathbf{R}(630 \mathrm{~nm})$, where the rising component becomes faster with the increasing dye concentration (Table 2).

Table 2. TA Kinetic Parameters for DPP_A and DPP_R on $\mathrm{Al}_{2} \mathrm{O}_{3}$ Observed at 710 and $630 \mathrm{~nm}$, Respectively ${ }^{a}$

\begin{tabular}{ccccccc} 
& \multicolumn{2}{c}{ DPP_A } & & \multicolumn{2}{c}{ DPP_R } \\
\cline { 2 - 3 } \cline { 5 - 6 } low & rise $\tau_{\text {ave }}(\mathrm{ps})$ & decay $\tau_{\text {ave }}(\mathrm{ps})$ & & rise $\tau_{\text {ave }}(\mathrm{ps})$ & decay $\tau_{\text {ave }}(\mathrm{ps})$ \\
mid & 54 & 18 & long & & & \\
high & 1.3 & 964 & & 14 & 477 \\
\end{tabular}

${ }^{a}$ The probe wavelengths were selected at a point where the intermolecular interaction dynamics are the least disturbed by the excited-state relaxations. The relationship $\Delta A(t)=A_{1} \exp \left(-t / \tau_{1}\right)+$ $A_{2} \exp \left(-t / \tau_{2}\right)+A_{3} \exp \left(-t / \tau_{3}\right)$, where $\Delta A(t)$ is the TA intensity, $A$ the amplitude, and $\tau$ the fitted decay time, was used to fit the data. The average time constant of the fits was calculated by using the relationship $\tau_{\text {ave }}=\sum_{i=1}^{n} A_{i} \tau_{i} / \sum_{i=1}^{n} A_{i}$.

The fact that the rising components are faster in the "high" film than in the "low" or "mid" film indicates that lateral intermolecular interactions occur more effectively when the intermolecular distance is shorter. ${ }^{16}$ Additionally, the similarity in the rising components of the DPP $\mathbf{R}$ traces in the "mid" (14 ps) and "high" (10 ps) films, which is not observed for the DPP_A traces, provide additional evidence that the lateral intermolecular interactions saturate faster in DPP_R than in DPP_A. On the basis of these observations, Scheme 1 illustrates a schematic diagram of the energy relaxation processes of DPP_A (black) and DPP_R (gray) in the solution phase (a) and on $\mathrm{Al}_{2} \mathrm{O}_{3}$ (b).

After formation of the charge-separated state (CSS) through the intermolecular interactions, relaxation from this state occurs for several hundred picoseconds for both dye-coated films. However, the kinetics of DPP_A are strongly affected by the absence of CDCA, as the process is accelerated from 946 to 277 ps, while the DPP_R film shows similar relaxation time constants of ca. 460 ps regardless of the presence of CDCA.
Scheme 1. Electronic Excited Energy Relaxation Dynamics of DPP_A (Black) and DPP_R (Gray) Loaded on $\mathrm{Al}_{2} \mathrm{O}_{3}$ Prepared by Dipping the Substrate into Solutions with 1:50 and 1:0 Ratios of Dye to CDCA

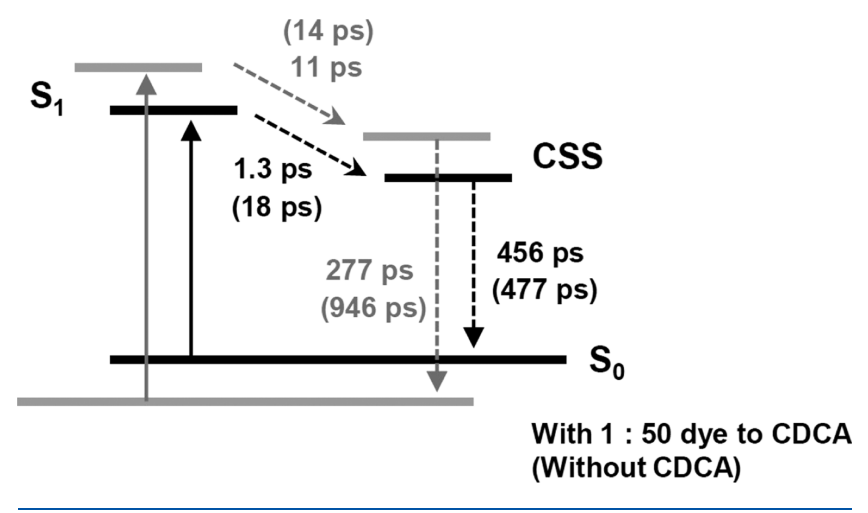

This characteristic also supports the fast saturation of intermolecular interactions between DPP_R dye molecules on the film.

To investigate the incoherent exciton recombination processes occurring in the dyes on $\mathrm{Al}_{2} \mathrm{O}_{3}$, pump fluencedependent TAS was conducted. Figure 6 shows the decay profiles probed at $710 \mathrm{~nm}$ for the DPP_A spectra and $630 \mathrm{~nm}$ for the DPP_R spectra. While DPP_R reveals no power dependency in the decay component, the TA decay profiles of DPP_A are sensitive to the pump power. As the pump fluence increases from 28 to $140 \mu \mathrm{J} / \mathrm{cm}^{2}$, the portion of the relatively fast $\tau_{1}(1.6 \mathrm{ps})$ component is enhanced to $44 \%$, which is a strong indication of exciton-exciton annihilation, or incoherent collision between excitons (Table 3)..$^{30,34-38}$

\section{DISCUSSION}

\subsection{Donor Effects on the Intermolecular Interactions} between DPP_A Dye Molecules in the Solution and Solid Phases. We have revealed the effect of the donor on the intermolecular interactions between DPP-based sensitizers in solution by investigating the photophysical dynamics through TA measurements. A gradual shift in the newly formed band to shorter wavelengths occurs for only DPP_A, and an undefined isosbestic point is observed (Figure 3) even though the TA spectra of DPP_A and DPP_R both contain a new band arising from intermolecular interactions in the high-concentration solutions. This disturbance can be interpreted as the contributions of various partially delocalized excitons to the 
(a) DPP_A

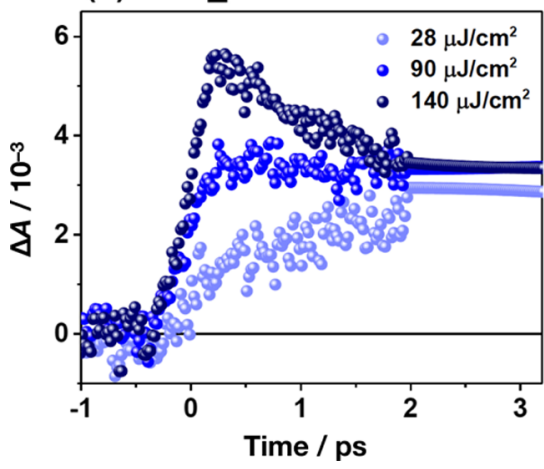

(b) DPP_R

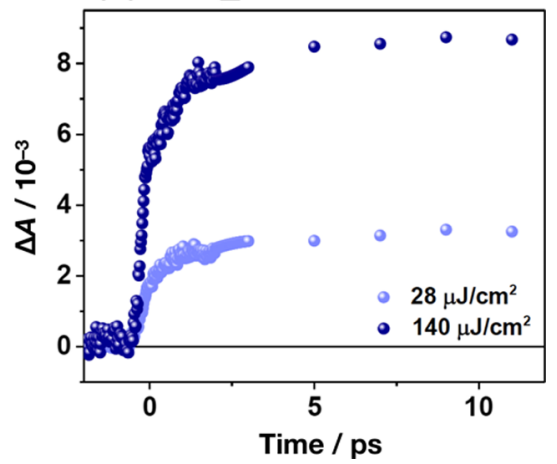

Figure 6. TA kinetic profiles of DPP_A (a) and DPP_R (b) on $\mathrm{Al}_{2} \mathrm{O}_{3}$ illustrating the pump power dependence. In the experiment, the pump energy fluence was increased from 28 to $140 \mu \mathrm{J} / \mathrm{cm}^{2}$. The probe wavelengths of DPP_A and DPP_R were 710 and $630 \mathrm{~nm}$, respectively.

Table 3. TA Absorption Kinetic Parameters for DPP_A on $\mathrm{Al}_{2} \mathrm{O}_{3}{ }^{a}$

$\begin{array}{llcc} & \tau_{1}(\mathrm{ps}) & \tau_{2}(\mathrm{ps}) & \tau_{3}(\mathrm{ps}) \\ 28 \mu \mathrm{J} / \mathrm{cm}^{2} & & 42(46 \%) & 929(54 \%) \\ 90 \mu \mathrm{J} / \mathrm{cm}^{2} & 1.6(5 \%) & 42(47 \%) & 929(48 \%) \\ 140 \mu \mathrm{J} / \mathrm{cm}^{2} & 1.6(44 \%) & 42(35 \%) & 929(21 \%)\end{array}$

${ }^{a_{T}}$ The relationship $\Delta A(t)=A_{1} \exp \left(-t / \tau_{1}\right)+A_{2} \exp \left(-t / \tau_{2}\right)+A_{3}$ $\exp \left(-t / \tau_{3}\right)$, where $\Delta A(t)$ is the TA intensity, $A$ is the amplitude, and $\tau$ is the fitted decay time, was used to fit the data. The normalized amplitude percentage, that is, $\left[A_{i} /\left(A_{1}+A_{2}+A_{3}\right)\right] \times 100$, is noted in parenthesis.

intermolecular interactions. This explanation is supported by the fact that the perturbed region nicely overlaps with the point at which the intermolecular interactions between DPP $\mathbf{R}$ dye molecules appear and clear isosbestic points are observed in the TA spectra of DPP_R regardless of the dye concentration.

In more detail, the solution environment could promote the generation of partially delocalized excitons. In the flexible environment, the motion of the more complex DPP_A structure facilitates deformation of the dye molecules into distorted structures, such as crooked or bent ones, under highly congested conditions, thereby easily introducing localized excitons within a dye molecule. Additionally, the asymmetric molecular structure of DPP_A induced by PhDPPTh installation ${ }^{18,39}$ can also enhance the probability of random distortion.

This interpretation is supported by the concentrationdependent steady-state absorption spectra of DPP_A in the solution phase (Supporting Information, Figure S2 and Table S3). In the normalized absorption spectra, the intensity ratio of the high-energy band $\left(I_{\mathrm{H}}\right)$ in the UV region to the low-energy band $\left(I_{\mathrm{L}}\right)$ in the visible region increases from 0.2 to 0.54 when the DPP_A concentration changes from 15 to $130 \mu \mathrm{M}$. The increase in the portion of the high-energy band, which is responsible for the transition into the partially delocalized excited state, ${ }^{18,40}$ explains the growing contribution of partially delocalized excitons in the excited state, which suggests the presence of additional intermolecular interactions arising from the localized excitons interacting with the delocalized ones upon photoexcitation. In contrast to DPP_A, the intensity ratio in the DPP_R absorption spectrum remains at a constant value of 1.1 regardless of the dye concentration. This observation is in line with the TA results, which show clear isosbestic points for all dye concentrations. The additional participation of partially delocalized DPP_A excitons in the intermolecular interactions also explains why the rising time of DPP_A (2.3 ps) is much faster than that of DPP_R (80 ps) in the solution phase.

Intermolecular interactions are still observed for the dyes adsorbed on the $\mathrm{Al}_{2} \mathrm{O}_{3}$ film, but some photophysical aspects change according to the environment. In comparison to the change in the TA spectra of DPP_A in solution, the band arising from the lateral intermolecular interactions is less blueshifted when going from the "mid" to "high" films. This result indicates that the localized excitons within DPP_A have minor contributions in the lateral intermolecular interactions, unlike the case in solution. This difference may arise because the DPP_A dye molecules on the film adopt a regularly ordered configuration. This ordered arrangement of DPP_A molecules on the film is further supported by the steady-state absorption spectra, whose intensity ratio between the bands in the UV and visible regions remains constant at ca. 0.8 in all film samples (Supporting Information, Figure S1, Table S3). This result reveals that structural distortion is not accelerated in the congested film environment unlike in the solution phase.

One explanation for the gradual decrease in random structural disorder in the DPP_A film is the occurrence of dipole-dipole interactions between neighboring dye molecules. As the intermolecular distance becomes shorter, the highly electron-rich TPA group interacts with the relatively electron-poor DPP core in an adjacent dye molecule, naturally resulting in an eclipsed configuration of the dye molecules on the surface. The preference for the slanted molecular arrangement is supported by the observation of an intense Jaggregate band in the absorption spectrum of the highconcentration DPP_A film, as shown in the inset of Figure 2a. Because of this molecular configuration, CT excitons, wherein an electron and a hole are localized on neighboring molecules, ${ }^{41-44}$ can be readily introduced among the DPP_A molecules upon photoexcitation. As supporting evidence, Ren et al. showed through grazing-incidence X-ray diffraction experiments that a well-ordered dye arrangement significantly affected the generation of intermolecular donoracceptor interactions. ${ }^{45}$

Another reason for the less blue-shifted spectral feature in the TA spectra of the high-concentration DPP_A film is the Stark effect arising from the presence of charged species, which are products of lateral intermolecular interactions, on the surface. ${ }^{46,47}$ Cappel et al. suggested the possibility that charge separation could occur through exciton formation as a result of 
(a) DPP_A

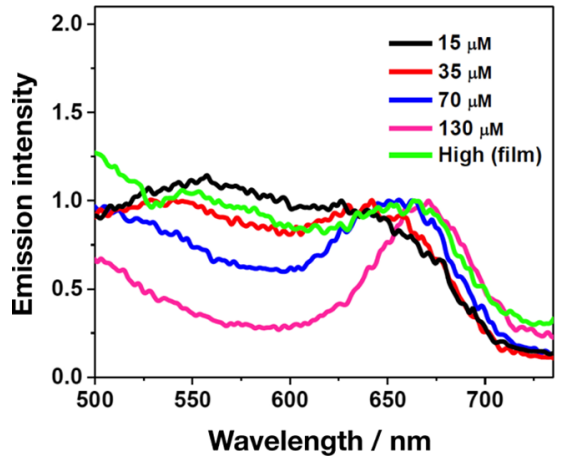

(b) DPP_R

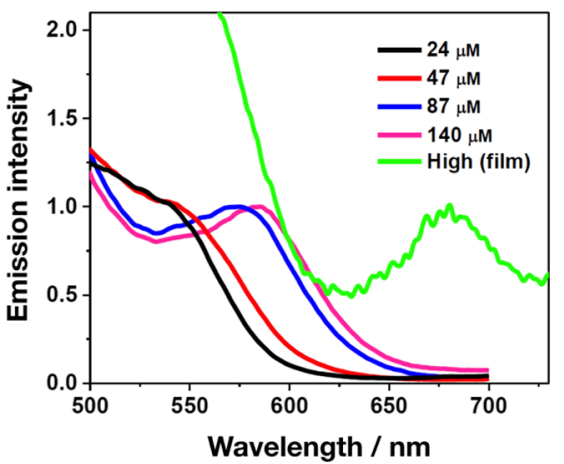

Figure 7. Normalized excitation spectra of DPP_A (a) and DPP_R (b) in solutions with different dye concentrations. The emission was recorded at 770 and $720 \mathrm{~nm}$, respectively. The spectra of the "high" films, which have a 1:0 ratio of dye to CDCA, were also recorded for both dyes by observing the $770 \mathrm{~nm}$ emission. All spectra were normalized with respect to the low-energy band.

lateral interactions between the molecules of an organic dye, $\mathrm{D} 131$, adsorbed on an $\mathrm{Al}_{2} \mathrm{O}_{3}$ film. ${ }^{16}$ Indeed, the TA spectra of the DPP_A and DPP_R films fabricated without the coadsorbent, CDCA, nicely overlap with the ones measured on $\mathrm{TiO}_{2}$ (Supporting Information, Figure S3); the peaks that grow with an increase in the amount of dye loaded on $\mathrm{Al}_{2} \mathrm{O}_{3}-$ in the region above $700 \mathrm{~nm}$ and the peak at ca. $630 \mathrm{~nm}$ in the case of DPP_A and DPP_R, respectively-match with the long-lived bands in the TA spectra on $\mathrm{TiO}_{2}$ films. Therefore, the peaks may originate from oxidized dye molecules formed through lateral intermolecular interactions on $\mathrm{Al}_{2} \mathrm{O}_{3}$ and interfacial electron transfer from the dye to $\mathrm{TiO}_{2}{ }^{48-50}$ This result suggests that the charged species formed from the lateral intermolecular interactions on $\mathrm{Al}_{2} \mathrm{O}_{3}$ cause the Stark effect, and that the resulting spectral red shift counteracts the blue shift caused by the lateral intermolecular interactions between localized excitons. This spectral shift cancelation is evident in Figure $4 \mathrm{~b}, \mathrm{c}$; at ca. $510 \mathrm{~nm}$, which corresponds to a point at which the absorbance is not disturbed by the lateral interactions, the gradual red shift caused by the Stark effect is clearly observed.

With this prominent red shift in the TA spectra, the fast rising component (1.3 ps) in the TA kinetics of the DPP_A film implies that the driving force for the formation of lateral intermolecular interactions is larger for DPP_A than for DPP_R. This analysis is supported by the observation that the absorbance of the $\mathrm{H}$ - and J-type aggregates in the concentrated films is more intense for DPP_A than for DPP_R. Because $\mathrm{H}$ and J-type aggregates are attributed to exciton splitting, which concurrently produces raised and lowered energy levels, their formation increases the energetic disorder. ${ }^{25,26}$ Given that the local energy differences between the loaded dyes are assumed to be the main reason for the lateral intermolecular interactions, ${ }^{16}$ lateral interactions are more easily induced in DPP_A than in DPP_R.

On the basis of comparison of the dynamics in each phase, we reached the conclusion that the role of the electron-rich TPA donor of DPP A in forming the intermolecular interactions changes with the environment; the donor enhances the participation of partially delocalized excitons in the solution phase, while it introduces CT excitons in the solid phase through the formation of a highly organized packing configuration.

4.2. Excitonic State Dynamics of the DPP_R Film. Upon photoexcitation, fewer CT excitons are generated in the
DPP_R film than in the DPP_A film because of the absence of a strong donor group in the former. The absence of the bulky donor moiety enables a relatively planar molecular geometry to be adopted, increasing the packing density through the formation of intermolecular $\pi-\pi$ interactions between neighboring dye molecules. ${ }^{51}$ This $\pi-\pi$ interaction leads to the formation of excimer-like excited states, ${ }^{52,53}$ in which a pair of DPP $\mathbf{R}$ molecules have a much shorter intermolecular distance in the excited state than in the ground state. ${ }^{54}$ The presence of excimer-like excited states is demonstrated by pump fluence-dependent TA measurements, which show the absence of an exciton-exciton annihilation process (Figure 6). One of the factors deciding the occurrence of an annihilation process is the number of excitons. ${ }^{30,36,55}$ In the DPP $\mathbf{R}$ film, the number of excitons generated per unit area is reduced because the strong intermolecular $\pi-\pi$ interactions delocalize the excitons over neighboring dye molecules rather than the excitons being localized on a single molecule. This delocalization prevents the occurrence of the incoherent annihilation process. On the other hand, the bulky donor group on DPP_A inhibits the formation of $\pi-\pi$ interactions between neighboring DPP cores in the excited state. ${ }^{51}$ Additionally, the complex molecular structure can facilitate the participation of several localized excitons, which accelerates the annihilation process. Ultimately, a relatively large number of excitons is generated from a high density of photons in the DPP_A film, and this large number enhances the probability of incoherent recombination between excitons, in contrast to the situation in the DPP_R film. The process is observed as a substantial contribution of the fast deactivation kinetics (1.6 ps) at a high pump fluence.

Moreover, as shown in Figure 7, the significant red shift observed in the excitation spectrum of the DPP_R film provides additional evidence of excimer-like excited-state formation. As the solution becomes more concentrated, both dyes show a gradual red shift that can be perceived as the formation of traces corresponding to a newly formed excited state arising from intermolecular interactions. ${ }^{25,26,56}$ Interestingly, the "high" film of DPP_R shows fluorescence in the excitation spectrum at much longer wavelengths than the concentrated solution, whereas the "high" film of DPP_A does not display any significant spectral shift. The red-shifted absorption threshold of the adsorbed dye molecules compared to their spectra in solution is generally explained by the enhanced planarity of the molecules. Intermolecular inter- 
actions can, however, also be the cause of the additional decrease in the excitation energy. ${ }^{23,57}$ Thus, the substantial change in the DPP_R film absorption suggests that excitons on neighboring $\mathrm{DPP}^{-}$cores are fused through strong $\pi-\pi$ intermolecular interactions, thereby substantially lowering the absorption threshold energy.

Interestingly, there is evidence of the involvement of an excimer-like excited state in the lateral intermolecular interactions between DPP_R dye molecules. Figure 5 shows that fast saturation of the rising component at $630 \mathrm{~nm}$ is observed in the kinetic profiles. In more detail, the excimer-like excited state generates a stack-like configuration that fuses independent excitons together, thus causing the amount of adsorbed dye to become insignificant after a certain concentration. Therefore, if the excimer-like excited state participates in the lateral intermolecular interactions, the reaction should also display saturation after a certain concentration. Indeed, this relationship is clearly visible in Figure 4, where the "mid" and "high" DPP_R films show similar rising components at $630 \mathrm{~nm}$, together with similar TA spectra. In short, this fast saturation characteristic demonstrates that the excimer-like excited state is associated with the lateral intermolecular interactions. Additionally, the fast saturation observed in the DPP_R film naturally supports the hypothesis that lateral interactions occur less efficiently in the highly concentrated DPP_R film than in the DPP_A film. Certainly, this inefficiency is revealed in the spectrum of the "high" DPP_R film, where a spectral red shift arising from the Stark effect is not clearly observed, unlike the results for the DPP_A film. This absence of the Stark effect means that the charge carrier density generated by the lateral intermolecular interactions is low. Therefore, we argue that the relatively inefficient lateral intermolecular interactions between DPP $\mathbf{R}$ dye molecules originate from the characteristics of an excimerlike excited state, which is also responsible for the weak local energy disorder that acts as a driving force.

Scheme 2 illustrates the exciton characteristics of each dye involved in the lateral intermolecular interactions. Even though

Scheme 2. Excitonic States Formed in the Concentrated DPP_A (a) and DPP_R (b) Films upon Photoexcitation ${ }^{a}$

(a) DPP_A

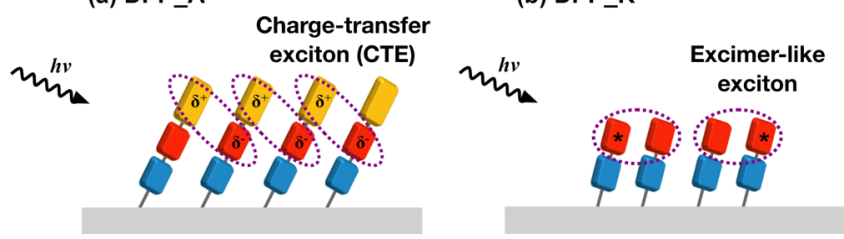

${ }^{a_{\text {The }}}$ TPA donor group, DPP core, and anchoring group are represented by yellow, red, and blue blocks, respectively. A CT exciton, mainly lying in the donor and neighboring DPP core, is observed in DPP_A. On the other hand, an excimer-like excited state (exciton) is induced in DPP_R through the formation of strong $\pi-\pi$ interactions between neighboring DPP cores.

the metal oxide has a mesoporous morphology, considering the small calculated area occupied by a single molecule $\left(2.69 \mathrm{~nm}^{2}\right.$, Supporting Information Table S1) with respect to the average surface area of a single nanoparticle $\left(1256 \mathrm{~nm}^{2}\right)$, Scheme 2 can be valid for a real device. Additionally, the high porosity of the mesoporous film (0.67) reduces the chance for dyes to become superimposed on each other, as they are adsorbed on different nanoparticles.

Together with the intramolecular CT strength, the type of exciton formed in the dye can be one of the crucial factors that affect the solar cell efficiency. Especially, the CT excitons that form on the donor-containing DPP_A sensitizers can improve the efficiency of the solar cell through the free carrier products generated after the CT excitons, as CT excitons are considered an intermediate stage of charge separation into free carriers. $^{52,58}$ By contrast, the excimer-like excited state of DPP_R acts as a trap site for excitons or charge carriers ${ }^{59-61}$ and may delay charge transport, thereby deteriorating the solar cell efficiency. This understanding is beneficial for elucidating the advantages of the $\mathrm{D}-\pi-\mathrm{A}$ motif as an efficient dye sensitizer structure, not only for DPP-based dyes but also for other metal-free organic dyes.

\section{CONCLUSIONS}

The photodynamics of DPP chromophore-based $\mathrm{D}-\pi-\mathrm{A}$ sensitizers DPP_A and DPP_R in solution and adsorbed on the surface of alumina were studied by steady-state and ultrafast TA spectroscopies. The effect of the bulky donor moiety on the intermolecular interactions was particularly scrutinized. Compared with the dynamics in solution, the strong electron-rich donor group present in the DPP_A molecules facilitates the generation of $\mathrm{CT}$ excitons upon photoexcitation and lateral electron transfer between neighboring dye molecules adsorbed on the solid film. The ordering of molecules in the adsorbed layer and the tilting of the molecules on the surface lead to the formation of $\mathrm{H}$ - and J-aggregates that favor charge separation through efficient charge and energy delocalization. Lateral intermolecular interactions were clearly observed in the form of a Stark effect signal in the timeresolved spectral measurements. On the other hand, the pump fluence-dependent transient absorption and excitation spectra showed that the formation of intermolecular $\pi$ - $\pi$ interactions between DPP_R dye molecules on $\mathrm{Al}_{2} \mathrm{O}_{3}$ induces excimer-like excited states that delocalize the exciton over more than one dye molecule. As a consequence, weaker intermolecular interactions occur in the highly concentrated DPP_R dye film than in the highly concentrated DPP_A dye film.

Summarizing the investigation, we show that a highly electron-rich donor plays an important role in deciding which type of exciton is formed and then participates in lateral intermolecular interactions between dye molecules adsorbed on the surface of $\mathrm{Al}_{2} \mathrm{O}_{3}$. Electron donor moieties are ubiquitous in the organic dye sensitizers used for solar energy conversion applications, where they facilitate a decrease in the excitation energy of the dyes and enable them to absorb strongly in the red part of the solar spectrum. When designing $\mathrm{D}-\pi-\mathrm{A}$ type sensitizers for use in nanocrystalline DSSCs, it is important to consider the effect of the enhanced lateral intermolecular interactions that arise from these donor groups, as they may affect the interfacial electron injection dynamics. The effect of lateral intermolecular interactions on the electron transfer mechanisms of DSSCs based on DPP $\mathbf{A}$ and DPP $\mathbf{R}$ dye sensitizers adsorbed on the surface of $\overline{\mathrm{TiO}}_{2}$ and in the presence of a redox-active electrolyte will be addressed in a separate paper. ${ }^{19}$ 


\section{ASSOCIATED CONTENT}

\section{S Supporting Information}

The Supporting Information is available free of charge on the ACS Publications website at DOI: 10.1021/acs.jpcc.8b04815.

Synthetic procedure for the DPP_R dye molecule and additional figures and tables reporting details of steadystate and time-resolved data (PDF)

\section{AUTHOR INFORMATION}

\section{Corresponding Author}

*E-mail: je.moser@epfl.ch.

ORCID

Jacques-E. Moser: 0000-0003-0747-4666

Notes

The authors declare no competing financial interest.

\section{ACKNOWLEDGMENTS}

Financial support by the Swiss National Science Foundation (grant no. 2000021 157135) and NCCR-MUST, a research instrument of the Swiss NSF, is gratefully acknowledged. The authors thank the Technician Training Laboratory of the Institute of Chemical Sciences and Engineering of EPFL, its apprentices and its supervisor, Dr. Luke Harris, for the synthesis of the DPP_R dye.

\section{REFERENCES}

(1) Hagfeldt, A.; Boschloo, G.; Sun, L.; Kloo, L.; Pettersson, H. DyeSensitized Solar Cells. Chem. Rev. 2010, 110, 6595-6663.

(2) Clifford, J. N.; Martínez-Ferrero, E.; Viterisi, A.; Palomares, E. Sensitizer Molecular Structure-Device Efficiency Relationship in Dye Sensitized Solar Cells. Chem. Soc. Rev. 2011, 40, 1635-1646.

(3) Mishra, A.; Fischer, M. K. R.; Bäuerle, P. Metal-Free Organic Dyes for Dye-Sensitized Solar Cells: From Structure: Property Relationships to Design Rules. Angew. Chem., Int. Ed. 2009, 48, 2474-2499.

(4) Zollinger, H. Color Chemistry: Syntheses, Properties, and Applications of Organic Dyes and Pigments; Wiley, 2003.

(5) Katono, M.; Wielopolski, M.; Marszalek, M.; Bessho, T.; Moser, J.-E.; Humphry-Baker, R.; Zakeeruddin, S. M.; Grätzel, M. Effect of Extended $\pi$-Conjugation of the Donor Structure of Organic DA $-\pi-\mathrm{A}$ Dyes on the Photovoltaic Performance of Dye-Sensitized Solar Cells. J. Phys. Chem. C 2014, 118, 16486-16493.

(6) Zhang, X.; Mao, J.; Wang, D.; Li, X.; Yang, J.; Shen, Z.; Wu, W.; Li, J.; Ågren, H.; Hua, J. Comparative Study on Pyrido[3,4B]Pyrazine-Based Sensitizers by Tuning Bulky Donors for DyeSensitized Solar Cells. ACS Appl. Mater. Interfaces 2015, 7, 27602771.

(7) Wang, C.-L.; Hu, J.-Y.; Wu, C.-H.; Kuo, H.-H.; Chang, Y.-C.; Lan, Z.-J.; Wu, H.-P.; Wei-Guang Diau, E.; Lin, C.-Y. Highly Efficient Porphyrin-Sensitized Solar Cells with Enhanced Light Harvesting Ability beyond $800 \mathrm{~nm}$ and Efficiency Exceeding 10\%. Energy Environ. Sci. 2014, 7, 1392-1396.

(8) Busby, E.; Xia, J.; Wu, Q.; Low, J. Z.; Song, R.; Miller, J. R.; Zhu, X.-Y.; Campos, L. M.; Sfeir, M. Y. A Design Strategy for Intramolecular Singlet Fission Mediated by Charge-Transfer States in Donor-Acceptor Organic Materials. Nat. Mater. 2015, 14, 426433.

(9) Clarke, T. M.; Durrant, J. R. Charge Photogeneration in Organic Solar Cells. Chem. Rev. 2010, 110, 6736-6767.

(10) Zhong, C.; Choi, H.; Kim, J. Y.; Woo, H. Y.; Nguyen, T. L.; Huang, F.; Cao, Y.; Heeger, A. J. Ultrafast Charge Transfer in Operating Bulk Heterojunction Solar Cells. Adv. Mater. 2015, 27, 2036-2041.

(11) Snaith, H. J.; Petrozza, A.; Ito, S.; Miura, H.; Grätzel, M. Charge Generation and Photovoltaic Operation of Solid-State Dye-
Sensitized Solar Cells Incorporating a High Extinction Coefficient Indolene-Based Sensitizer. Adv. Funct. Mater. 2009, 19, 1810-1818.

(12) Moser, J.-E. Dynamics of Interfacial and Surface Electron Transfer Processes. In Dye-Sensitized Solar Cells; Kalyanasundaram, K., Ed.; EFPL Press: Lausanne, 2010.

(13) Ehret, A.; Stuhl, L.; Spitler, M. T. Spectral Sensitization of $\mathrm{TiO}_{2}$ Nanocrystalline Electrodes with Aggregated Cyanine Dyes. J. Phys. Chem. B 2001, 105, 9960-9965.

(14) Kawasaki, M.; Aoyama, S. High Efficiency Photocurrent Generation by Two-Dimensional Mixed J-Aggregates of Cyanine Dyes. Chem. Commun. 2004, 988-989.

(15) Khazraji, A. C.; Hotchandani, S.; Das, S.; Kamat, P. V. Controlling Dye (Merocyanine-540) Aggregation on Nanostructured $\mathrm{TiO}_{2}$ Films. An Organized Assembly Approach for Enhancing the Efficiency of Photosensitization. J. Phys. Chem. B 1999, 103, 46934700.

(16) Cappel, U. B.; Moia, D.; Bruno, A.; Vaissier, V.; Haque, S. A.; Barnes, P. R. F. Evidence for Photo-Induced Charge Separation between Dye Molecules Adsorbed to Aluminium Oxide Surfaces. Sci. Rep. 2016, 6, 21276.

(17) Motley, T. C.; Meyer, G. J. Intramolecular Electronic Coupling Enhances Lateral Electron Transfer across Semiconductor Interfaces. J. Phys. Chem. C 2018, 122, 14420-14424.

(18) Yum, J.-H.; Holcombe, T. W.; Kim, Y.; Rakstys, K.; Moehl, T.; Teuscher, J.; Delcamp, J. H.; Nazeeruddin, M. K.; Grätzel, M. BlueColoured Highly Efficient Dye-Sensitized Solar Cells by Implementing the Diketopyrrolopyrrole Chromophore. Sci. Rep. 2013, 3, 2446.

(19) Bahng, H.-W.; Hagfeldt, A.; Moser, J.-E. Donor Effect on PhotoInduced Interfacial Charge Transfer Dynamics for D- $\pi$-A Diketopyrrolopyrole Dye-Sensitizers Adsorbed on Mesoporous $\mathrm{TiO}_{2}$. J. Phys. Chem. C 2018, DOI: 10.1021/acs.jpcc.8b04819.

(20) Otsuka, Y.; Okamoto, Y.; Akiyama, H. Y.; Umekita, K.; Tachibana, Y.; Kuwabata, S. Photoinduced Formation of Polythiophene/ $\mathrm{TiO}_{2}$ Nanohybrid Heterojunction Films for Solar Cell Applications. J. Phys. Chem. C 2008, 112, 4767-4775.

(21) Matta, S. K.; Kakiage, K.; Makuta, S.; Veamatahau, A.; Aoyama, Y.; Yano, T.; Hanaya, M.; Tachibana, Y. Dye-Anchoring Functional Groups on the Performance of Dye-Sensitized Solar Cells: Comparison between Alkoxysilyl and Carboxyl Groups. J. Phys. Chem. C 2014, 118, 28425-28434.

(22) Yum, J. H.; Moon, S. J.; Humphry-Baker, R.; Walter, P.; Geiger, T.; Nüesch, F.; Grätzel, M.; Nazeeruddin, M. K. Effect of Coadsorbent on the Photovoltaic Performance of Squaraine Sensitized Nanocrystalline Solar Cells. Nanotechnology 2008, 19, 424005.

(23) Kirkus, M.; Wang, L.; Mothy, S.; Beljonne, D.; Cornil, J.; Janssen, R. A. J.; Meskers, S. C. J. Optical Properties of Oligothiophene Substituted Diketopyrrolopyrrole Derivatives in the Solid Phase: Joint J- and H-Type Aggregation. J. Phys. Chem. A 2012, 116, 7927-7936.

(24) Eisfeld, A.; Briggs, J. S. The J- and H-Bands of Organic Dye Aggregates. Chem. Phys. 2006, 324, 376-384.

(25) Davydov, A. S. The Theory of Molecular Excitons. PhysicsUspekhi 1964, 7, 145-178.

(26) Kasha, M.; Rawls, H. R.; Ashraf El-Bayoumi, M. The Exciton Model in Molecular Spectroscopy. Pure Appl. Chem. 1965, 11, 371.

(27) Palomares, E.; Clifford, J. N.; Haque, S. A.; Lutz, T.; Durrant, J. $\mathrm{R}$. Control of Charge Recombination Dynamics in Dye Sensitized Solar Cells by the Use of Conformally Deposited Metal Oxide Blocking Layers. J. Am. Chem. Soc. 2003, 125, 475-482.

(28) Dworak, L.; Matylitsky, V. V.; Wachtveitl, J. Ultrafast Photoinduced Processes in Alizarin-Sensitized Metal Oxide Mesoporous Films. ChemPhysChem 2009, 10, 384-391.

(29) Luo, L.; Lin, C.-J.; Tsai, C.-Y.; Wu, H.-P.; Li, L.-L.; Lo, C.-F.; Lin, C.-Y.; Diau, E. W.-G. Effects of Aggregation and Electron Injection on Photovoltaic Performance of Porphyrin-Based Solar Cells with Oligo(phenylethynyl) Links inside $\mathrm{TiO}_{2}$ and $\mathrm{Al}_{2} \mathrm{O}_{3}$ Nanotube Arrays. Phys. Chem. Chem. Phys. 2010, 12, 1064-1071. 
(30) Bahng, H. W.; Yoon, M.-C.; Lee, J.-E.; Murase, Y.; Yoneda, T.; Shinokubo, H.; Osuka, A.; Kim, D. Ensemble and Single-Molecule Spectroscopic Study on Excitation Energy Transfer Processes in 1,3Phenylene-Linked Perylenebisimide Oligomers. J. Phys. Chem. B 2012, 116, 1244-1255.

(31) Concepcion, J. J.; Brennaman, M. K.; Deyton, J. R.; Lebedeva, N. V.; Forbes, M. D. E.; Papanikolas, J. M.; Meyer, T. J. Excited-State Quenching by Proton-Coupled Electron Transfer. J. Am. Chem. Soc. 2007, 129, 6968-6969.

(32) Porcal, G.; Bertolotti, S. G.; Previtali, C. M.; Encinas, M. V. Electron Transfer Quenching of Singlet and Triplet Excited States of Flavins and Lumichrome by Aromatic and Aliphatic Electron Donors. Phys. Chem. Chem. Phys. 2003, 5, 4123-4128.

(33) Iwai, S.; Murata, S.; Tachiya, M. Ultrafast Fluorescence Quenching by Electron Transfer and Fluorescence from the Second Excited State of a Charge Transfer Complex as Studied by Femtosecond Up-Conversion Spectroscopy. J. Chem. Phys. 1998, 109, 5963-5970.

(34) Brüggemann, B.; Herek, J. L.; Sundström, V.; Pullerits, T.; May, V. Microscopic Theory of Exciton Annihilation: Application to the LH2 Antenna System. J. Phys. Chem. B 2001, 105, 11391-11394.

(35) Bradforth, S. E.; Jimenez, R.; van Mourik, F.; van Grondelle, R.; Fleming, G. R. Excitation Transfer in the Core Light-Harvesting Complex (LH-1) of Rhodobacter Sphaeroides: An Ultrafast Fluorescence Depolarization and Annihilation Study. J. Phys. Chem. 1995, 99, 16179-16191.

(36) Trinkunas, G.; Herek, J. L.; Polívka, T.; Sundström, V.; Pullerits, T. Exciton Delocalization Probed by Excitation Annihilation in the Light-Harvesting Antenna LH2. Phys. Rev. Lett. 2001, 86, $4167-4170$.

(37) Brüggemann, B.; May, V. Exciton Exciton Annihilation Dynamics in Chromophore Complexes. II. Intensity Dependent Transient Absorption of the LH2 Antenna System. J. Chem. Phys. 2004, 120, 2325-2336.

(38) Müller, M. G.; Hucke, M.; Reus, M.; Holzwarth, A. R. Annihilation Processes in the Isolated D1-D2-cyt-b559 Reaction Center Complex of Photosystem II. An Intensity-Dependence Study of Femtosecond Transient Absorption. J. Phys. Chem. 1996, 100, 9537-9544.

(39) Grzybowski, M.; Gryko, D. T. Diketopyrrolopyrroles: Synthesis, Reactivity, and Optical Properties. Adv. Opt. Mater. 2015, 3, 280-320.

(40) Fan, W.; Tan, D.; Zhang, Q.; Wang, H. Computational Study of Diketopyrrolopyrrole-Based Organic Dyes for Dye Sensitized Solar Cell Applications. J. Mol. Graphics Modell. 2015, 57, 62-69.

(41) Yokoyama, M.; Endo, Y.; Matsubara, A.; Mikawa, F. H. Mechanism of Extrinsic Carrier Photogeneration in Poly-N-vinylcarbazole. II. Quenching of Exciplex Fluorescence by Electric Field. J. Chem. Phys. 1981, 75, 3006-3011.

(42) Mihailetchi, V. D.; Koster, L. J. A.; Hummelen, J. C.; Blom, P. W. M. Photocurrent Generation in Polymer-Fullerene Bulk Heterojunctions. Phys. Rev. Lett. 2004, 93, 216601.

(43) Peumans, P.; Forrest, S. R. Separation of Geminate ChargePairs at Donor-Acceptor Interfaces in Disordered Solids. Chem. Phys. Lett. 2004, 398, 27-31.

(44) Martínez, J. P.; Osuna, S.; Solà, M.; Voityuk, A. Extent of Charge Separation and Exciton Delocalization for Electronically Excited States in a Triphenylamine- $\mathrm{C}_{60}$ Donor-Acceptor Conjugate: A Combined Molecular Dynamics and TD-DFT Study. Theor. Chem. Acc. 2015, 134, 12.

(45) Ren, Y.; Hiszpanski, A. M.; Whittaker-Brooks, L.; Loo, Y.-L. Structure-Property Relationship Study of Substitution Effects on Isoindigo-Based Model Compounds as Electron Donors in Organic Solar Cells. ACS Appl. Mater. Interfaces 2014, 6, 14533-14542.

(46) Cappel, U. B.; Feldt, S. M.; Schöneboom, J.; Hagfeldt, A.; Boschloo, G. The Influence of Local Electric Fields on Photoinduced Absorption in Dye-Sensitized Solar Cells. J. Am. Chem. Soc. 2010, 132, 9096-9101.
(47) Bairu, S. G.; et al. Ultrafast Interfacial Charge-Transfer Dynamics in a Donor- $\pi$-Acceptor Chromophore Sensitized $\mathrm{TiO}_{2}$ Nanocomposite. J. Phys. Chem. C 2013, 117, 4824-4835.

(48) Oum, K.; Lohse, P. W.; Klein, J. R.; Flender, O.; Scholz, M.; Hagfeldt, A.; Boschloo, G.; Lenzer, T. Photoinduced Ultrafast Dynamics of the Triphenylamine-Based Organic Sensitizer D35 on $\mathrm{TiO}_{2}, \mathrm{ZrO}_{2}$ and in Acetonitrile. Phys. Chem. Chem. Phys. 2013, 15, 3906-3916.

(49) Fakis, M.; Hrobárik, P.; Yushchenko, O.; Sigmundová, I.; Koch, M.; Rosspeintner, A.; Stathatos, E.; Vauthey, E. Excited State and Injection Dynamics of Triphenylamine Sensitizers Containing a Benzothiazole Electron-Accepting Group on $\mathrm{TiO}_{2}$ and $\mathrm{Al}_{2} \mathrm{O}_{3}$ Thin Films. J. Phys. Chem. C 2014, 118, 28509-28519.

(50) Kuciauskas, D.; Monat, J. E.; Villahermosa, R.; Gray, H. B.; Lewis, N. S.; McCusker, J. K. Transient Absorption Spectroscopy of Ruthenium and Osmium Polypyridyl Complexes Adsorbed onto Nanocrystalline $\mathrm{TiO}_{2}$ Photoelectrodes. J. Phys. Chem. B 2002, 106, 9347-9358.

(51) Pop, F.; Lewis, W.; Amabilino, D. B. Solid State Supramolecular Structure of Diketopyrrolopyrrole Chromophores: Correlating Stacking Geometry with Visible Light Absorption. CrystEngComm 2016, 18, 8933-8943.

(52) Pope, M.; Swenberg, C. E. Electronic Processes in Organic Crystals and Polymers; Oxford University Press, 1999.

(53) Schuller, J. A.; Karaveli, S.; Schiros, T.; He, K.; Yang, S.; Kymissis, I.; Shan, J.; Zia, R. Orientation of Luminescent Excitons in Layered Nanomaterials. Nat. Nanotechnol. 2013, 8, 271-276.

(54) West, B. A.; Womick, J. M.; McNeil, L. E.; Tan, K. J.; Moran, A. M. Influence of Vibronic Coupling on Band Structure and Exciton Self-Trapping in $\alpha$-Perylene. J. Phys. Chem. B 2011, 115, 5157-5167.

(55) Trinkunas, G. Probing of Molecular Aggregates with Exciton Annihilation. J. Lumin. 2003, 102-103, 532-535.

(56) Yanagisawa, S.; Yasuda, T.; Inagaki, K.; Morikawa, Y.; Manseki, K.; Yanagida, S. Intermolecular Interaction as the Origin of Red Shifts in Absorption Spectra of Zinc-Phthalocyanine from First-Principles. J. Phys. Chem. A 2013, 117, 11246-11253.

(57) Tzamalis, G.; Lemaur, V.; Karlsson, F.; Holtz, P. O.; Andersson, M.; Crispin, X.; Cornil, J.; Berggren, M. Fluorescence Light Emission at $1 \mathrm{eV}$ from a Conjugated Polymer. Chem. Phys. Lett. 2010, 489, 9295.

(58) Hoffmann, M.; Schmidt, K.; Fritz, T.; Hasche, T.; Agranovich, V. M.; Leo, K. The Lowest Energy Frenkel and Charge-Transfer Excitons in Quasi-One-Dimensional Structures: Application to Meptcdi and Ptcda Crystals. Chem. Phys. 2000, 258, 73-96.

(59) Magri, A.; Friederich, P.; Schäfer, B.; Fattori, V.; Sun, X.; Strunk, T.; Meded, V.; Hueso, L. E.; Wenzel, W.; Ruben, M. Charge Carrier Mobility and Electronic Properties of $\mathrm{Al}(\mathrm{Op})_{3}$ : Impact of Excimer Formation. Beilstein J. Nanotechnol. 2015, 6, 1107-1115.

(60) Köhler, A.; Bässler, H. Electronic Processes in Organic Semiconductors: An Introduction; Wiley, 2015.

(61) Guo, Z.; Lee, D.; Schaller, R. D.; Zuo, X.; Lee, B.; Luo, T.; Gao, H.; Huang, L. Relationship between Interchain Interaction, Exciton Delocalization, and Charge Separation in Low-Bandgap Copolymer Blends. J. Am. Chem. Soc. 2014, 136, 10024-10032. 



\section{Lateral Intermolecular Electronic Interactions of Diketopyrrolopyrrole D- $\pi$-A Solar Dye Sensitizers Adsorbed on Mesoporous Alumina}

\section{Supporting Information}

Hee-Won Bahng, ${ }^{1,3}$ Anders Hagfeldt, ${ }^{2,3}$ and Jacques-E. Moser ${ }^{1,3} *$

${ }^{1}$ Photochemical Dynamics Group, Institute of Chemical Sciences \& Engineering, École polytechnique fédérale de Lausanne, 1015 Lausanne, Switzerland

${ }^{2}$ Laboratory of Photomolecular Science, Institute of Chemical Sciences \& Engineering, École polytechnique fédérale de Lausanne, 1015 Lausanne, Switzerland

${ }^{3}$ Lausanne Centre for Ultrafast Science (LACUS), École polytechnique fedérale de Lausanne, 1015 Lausanne, Switzerland

* Corresponding author : E-mail : je.moser@epfl.ch 


\section{S1. Synthesis of the DPP_R dye}

Step1: methyl 3-oxo-3-(thiophen-2-yl)propanoate (2)<smiles>COC(=O)CC(=O)c1cccs1</smiles>

\section{LABE003}

$\mathrm{KOtBu}(9.24 \mathrm{~g}, 2.1 \mathrm{eq})$ and dimethylcarbonate $(7.07 \mathrm{~g}, 2.0 \mathrm{eq})$ were mixed in dry toluene (50 $\mathrm{mL}, 10 \mathrm{vol})$. The solution was heated at $100^{\circ} \mathrm{C}$. Acetyl thiophene $(5.0 \mathrm{~g}, 1.0 \mathrm{eq})$ was added over $3 \mathrm{~h}$ using a syringe pump. The reaction mixture was then left $\mathrm{O} / \mathrm{N}$ at $100^{\circ} \mathrm{C}$. Reaction was cooled to RT and poured onto ice $(67 \mathrm{~g}, 13 \mathrm{wt}$.). Layers were separated and aqueous phase was extracted with EtOAc $(50 \mathrm{~mL}, 10 \mathrm{vol})$. Organic phases were combined, dried over $\mathrm{MgSO}_{4}$, filtered and evaporated to dryness to finally obtain the expected crude product 2 $(11.02 \mathrm{~g}, 83 \%)$ as a brown oil. This material was used without purification in the next step. 1H NMR (400 MHz, Chloroform- $d$ ) $\delta 7.76(\mathrm{dd}, J=3.8,1.2 \mathrm{~Hz}, 1 \mathrm{H}), 7.72(\mathrm{dd}, J=4.9,1.1 \mathrm{~Hz}$, $1 \mathrm{H}), 7.17(\mathrm{dd}, J=5.0,3.8 \mathrm{~Hz}, 1 \mathrm{H}), 3.96(\mathrm{~s}, 2 \mathrm{H}), 3.77(\mathrm{~s}, 3 \mathrm{H})$.

Step 2: dimethyl 2-(thiophene-2-carbonyl)succinate (3)

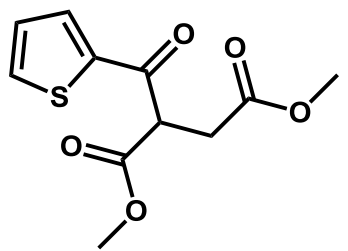

3

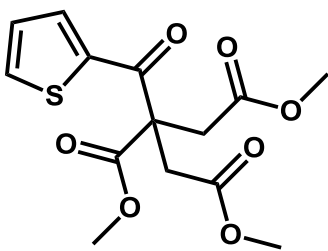

3b

\section{LABE008}

Crude methyl 3-oxo-3-(thiophen-2-yl)propanoate 2 (10.5g, $29.9 \mathrm{mmol}, 1.0 \mathrm{eq})$ was dissolved in acetone $(32 \mathrm{~mL}, 3 \mathrm{vol})$ and $\operatorname{DME}(21 \mathrm{ml}, 2 \mathrm{vol}) . \mathrm{K}_{2} \mathrm{CO}_{3}(13.06 \mathrm{~g}, 1.07 \mathrm{eq})$ was added followed by drop-wise addition of methyl bromo acetate $(9.35 \mathrm{~g}, 1.07 \mathrm{eq})$. Reaction was heated at $80^{\circ} \mathrm{C} \mathrm{O} / \mathrm{N}$ giving a brown suspension. Reaction mixture was cooled to RT and filtered over a sinter plate. The cake was washed with acetone $(50 \mathrm{~mL})$ and filtrate was evaporated to dryness yielding the expected crude product $3(15.04 \mathrm{~g}, 103 \%)$ as a brown oil. $1 \mathrm{H}-\mathrm{NMR}$ showed this crude material contained some bis alkylated byproduct $3 \mathrm{~b}(17 \% \mathrm{w} / \mathrm{w}$ according to $1 \mathrm{H}-\mathrm{NMR})$. This material was used without purification in the next step. $3: 1 \mathrm{H}$ NMR (400 MHz, Chloroform-d) $\delta 7.92(\mathrm{dd}, \mathrm{J}=3.9,1.1 \mathrm{~Hz}, 1 \mathrm{H}), 7.74$ (dd, J = 4.9, $1.2 \mathrm{~Hz}$, $1 \mathrm{H}), 7.19(\mathrm{dd}, \mathrm{J}=5.0,3.8 \mathrm{~Hz}, 1 \mathrm{H}), 4.73(\mathrm{t}, \mathrm{J}=7.2 \mathrm{~Hz}, 1 \mathrm{H}), 3.73(\mathrm{~s}, 3 \mathrm{H}), 3.70(\mathrm{~s}, 3 \mathrm{H}), 3.09$ (d, 
$\mathrm{J}=7.2 \mathrm{~Hz}, 2 \mathrm{H}) .3 \mathrm{~b}: 1 \mathrm{H} \mathrm{NMR}(400 \mathrm{MHz}$, Chloroformd) $\delta 7.78(\mathrm{~d}, \mathrm{~J}=3.8 \mathrm{~Hz}, 1 \mathrm{H}), 7.66(\mathrm{~d}, \mathrm{~J}$ $=4.9 \mathrm{~Hz}, 1 \mathrm{H}), 7.12-7.08(\mathrm{~m}, 1 \mathrm{H}), 3.75(\mathrm{~s}, 3 \mathrm{H}), 3.66(\mathrm{~s}, 4 \mathrm{H}), 3.56(\mathrm{~s}, 3 \mathrm{H}), 3.41(\mathrm{~s}, 4 \mathrm{H})$.

Step 3: methyl 5-oxo-2-(thiophen-2-yl)-4,5-dihydro-1H-pyrrole-3-carboxylate (4)

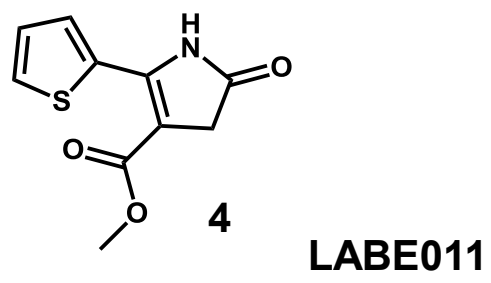

Crude dimethyl 2-(thiophene-2-carbonyl)succinate (3) (14.5g, $57 \mathrm{mmol}, 1 \mathrm{eq})$ was dissolved in $\mathrm{AcOH}(45 \mathrm{~mL}, 3.2 \mathrm{vol})$. Ammonium acetate $(43.1 \mathrm{~g}, 559 \mathrm{mmol}, 9.8 \mathrm{eq})$ was added. Reaction mixture was refluxed for $3 \mathrm{~h}$. It was then cooled to RT and poured onto acetone (200 $\mathrm{mL})$. Suspension was filtered over a sinter plate. The cake was washed with $\mathrm{MeOH}(5 \times 15 \mathrm{~mL})$ and finally dried under vacuum yielding the pure expected product (4) $5.68 \mathrm{~g}(44.7 \%)$ as a blue grey powder. $1 \mathrm{H}$ NMR (400 MHz, DMSO-d6) $\delta 10.85$ (s, 1H), 7.88 (ddd, J = 10.1, 4.8, $1.2 \mathrm{~Hz}, 2 \mathrm{H}), 7.20$ (dd, J = 5.1, 3.8 Hz, 1H), 3.67 (s, 3H), 3.44 (s, 2H).

Step 4: 3-(4-bromophenyl)-6-(thiophen-2-yl)-2,5-dihydropyrrolo[3,4-c]pyrrole-1,4-dione (5)

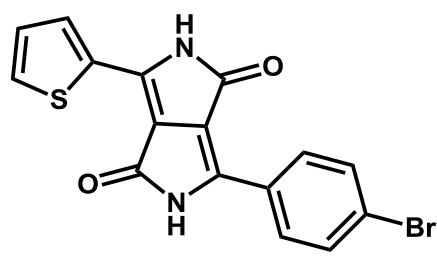

5

\section{LABE015}

$\mathrm{FeCl}_{3}$ (4 mg, $\left.0.025 \mathrm{mmol}, 0.001 \mathrm{eq}\right)$ was dissolved in dry tert-amylalcohol (28 mL, 5vol). $\mathrm{Na}$ $(1.44 \mathrm{~g}, 63 \mathrm{mmol}, 2.5 \mathrm{eq})$ was added in portions and mixture was heated to reflux for $1 \mathrm{~h}$. methyl5-oxo-2-(thiophen-2-yl)-4,5-dihydro- $1 H$-pyrrole-3-carboxylate (4) (5.5g, 25mmol, 1.0 eq) was added in one portion followed by 4-bromobenzonitrile ( $4.50 \mathrm{~g}, 25 \mathrm{mmol}, 1.0 \mathrm{eq})$. The purple reaction mixture was refluxed $\mathrm{O} / \mathrm{N}$ and then cooled to $\mathrm{RT}$. Mixture was diluted with $\mathrm{MeOH}(50 \mathrm{~mL})$. AcOH $(5.0 \mathrm{~mL})$ was added. The thick purple suspension was filtered, the cake washed with $\mathrm{MeOH}(3 \times 50 \mathrm{~mL})$ and dried under vacuum. Finally, the expected product (5) $(7.82 \mathrm{~g}, 84 \%)$ was isolated as a dark red solid. 1H NMR (400 MHz, DMSO- $d 6) \delta 11.58-$ 11.04 (brs, 2H), 8.36 (d, $J=8.4 \mathrm{~Hz}, 2 \mathrm{H}), 8.31(\mathrm{~d}, J=3.9 \mathrm{~Hz}, 1 \mathrm{H}), 8.00$ (d, $J=4.9 \mathrm{~Hz}, 1 \mathrm{H})$, $7.79(\mathrm{~d}, J=8.3 \mathrm{~Hz}, 2 \mathrm{H}), 7.33$ (t, $J=4.4 \mathrm{~Hz}, 1 \mathrm{H})$. 
Step 5: 3-(4-bromophenyl)-2,5-bis(2-ethylhexyl)-6-(thiophen-2-yl)-2,5-dihydropyrrolo[3,4c]pyrrole-1,4-dione (6)

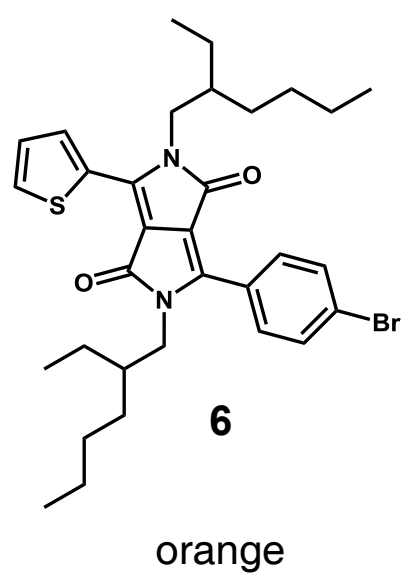

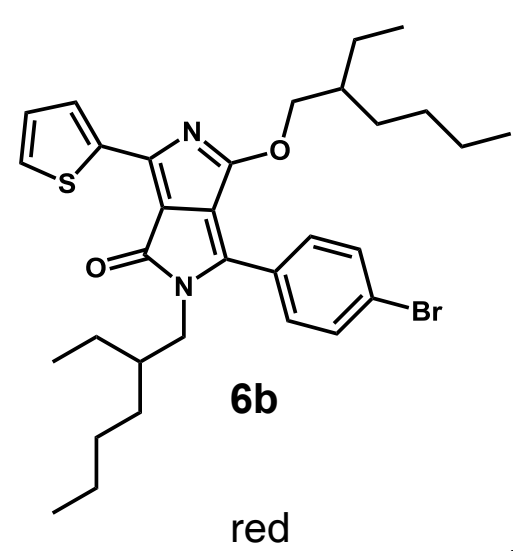

LABE018

3-(4-bromophenyl)-6-(thiophen-2-yl)-2,5-dihydropyrrolo[3,4-c]pyrrole-1,4-dione (5) (7.5 g, $20.1 \mathrm{mmol}, 1.0 \mathrm{eq})$ was suspended in dry NMP $(75 \mathrm{~mL}, 10 \mathrm{vol})$. KOtBu $(4.51 \mathrm{~g}, 40.2 \mathrm{mmol}$, $2.0 \mathrm{eq})$ was added and was vigorously stirred at $60^{\circ} \mathrm{C}$ for $30 \mathrm{~min}$. The very thick red reaction mixture became dark blue. 1-bromo-2-ethylhexane (23.29 g, $120.6 \mathrm{mmol}, 6.0 \mathrm{eq})$ was added dropwise at $60^{\circ} \mathrm{C}$ over $90 \mathrm{~min}$. The reaction was stirred $\mathrm{O} / \mathrm{N}$ at $60^{\circ} \mathrm{C}$. It was cooled to $\mathrm{RT}$, toluene $(75 \mathrm{~mL})$ was added. The mixture was filtered over a pad of silica $(30 \mathrm{~g})$. The pad was washed with toluene $(5 \times 75 \mathrm{~mL})$. The filtrates were combined and washed with water $(3 \times 50$ $\mathrm{mL})$ and brine $(50 \mathrm{~mL})$. The organic phase was evaporated to dryness yielding $23.8 \mathrm{~g}(198 \%)$ of a dark red oil. This crude material was purified by flash chromatography $\left(300 \mathrm{~g} \mathrm{SiO}_{2}\right.$, $\mathrm{DCM} /$ hex 50:50). 2 main products were isolated. After evaporation of the first pool of fraction, a by product characterized as the $\mathrm{N}, \mathrm{O}$-alkylated product $\mathbf{6 b}(0.83 \mathrm{~g}, 7 \%)$ was isolated as a red-purple solidifying oil. $1 \mathrm{H}$ NMR $(400 \mathrm{MHz}$, Chloroform- $d) \delta 8.50-8.41(\mathrm{~m}, 2 \mathrm{H})$, $8.30(\mathrm{dd}, J=4.1,1.1 \mathrm{~Hz}, 1 \mathrm{H}), 7.76(\mathrm{dd}, J=5.2,1.2 \mathrm{~Hz}, 1 \mathrm{H}), 7.65-7.55(\mathrm{~m}, 2 \mathrm{H}), 7.30-7.24$ $(\mathrm{m}, 2 \mathrm{H}), 4.62-4.49(\mathrm{~m}, 2 \mathrm{H}), 4.05-3.88(\mathrm{~m}, 2 \mathrm{H}), 1.81(\mathrm{dq}, J=12.3,6.2 \mathrm{~Hz}, 2 \mathrm{H}), 1.56-$ $1.18(\mathrm{~m}, 18 \mathrm{H}), 1.06-0.82(\mathrm{~m}, 12 \mathrm{H}) .13 \mathrm{C}$ NMR (101 MHz, Chloroform- $d$ ) $\delta 165.83,162.31$, $154.91,144.25,135.59,132.26,131.72,130.23,128.09,124.93,113.08,72.27,45.64$, $39.33,39.09,30.75,30.25,29.09,28.35,24.10,23.58,23.05,23.04,14.09,14.03$, $11.27,10.50 . \mathrm{m} / \mathrm{z}$ calculated for $\mathrm{C}_{32} \mathrm{H}_{41} \mathrm{BrN}_{2} \mathrm{O}_{2} \mathrm{~S}: 596.21,598.21$ found: $599.25(\mathrm{M}+\mathrm{H})$. The second pool of factions yielded the expected product $6(2.17 \mathrm{~g}, 18 \%)$ as a dark orange solidifying oil. 1H NMR (400 MHz, Chloroform- $d$ ) $\delta 8.96(\mathrm{dd}, J=3.9,1.2 \mathrm{~Hz}, 1 \mathrm{H}), 7.72-$ $7.60(\mathrm{~m}, 4 \mathrm{H}), 7.59-7.47(\mathrm{~m}, 1 \mathrm{H}), 7.31(\mathrm{dd}, J=5.1,3.9 \mathrm{~Hz}, 2 \mathrm{H}), 3.97(\mathrm{dt}, J=11.5,6.0 \mathrm{~Hz}$, $1 \mathrm{H}), 3.88-3.70(\mathrm{~m}, 2 \mathrm{H}), 1.84(\mathrm{~h}, J=6.5 \mathrm{~Hz}, 1 \mathrm{H}), 1.60-1.49(\mathrm{~m}, 2 \mathrm{H}), 1.44-0.99(\mathrm{~m}, 16 \mathrm{H})$, $0.98-0.68$ (m, 12H).13C NMR (101 MHz, Chloroform-d) $\delta 162.28,162.02,145.31$, $142.58,135.91,132.15,131.98,131.23,130.22,130.09$, $129.64,128.89$ (d, $J=17.4 \mathrm{~Hz})$, $128.61,128.52,127.53,125.17,109.95(\mathrm{~d}, J=6.2 \mathrm{~Hz}), 72.27,45.76,45.16,39.06(\mathrm{~d}, J=$ $1.1 \mathrm{~Hz}), 38.64(\mathrm{~d}, J=1.0 \mathrm{~Hz}), 30.64,30.30(\mathrm{~d}, J=1.4 \mathrm{~Hz}), 30.25(\mathrm{~d}, J=1.8 \mathrm{~Hz}), 28.40$, $28.26(\mathrm{~d}, J=1.2 \mathrm{~Hz}), 23.71,23.59,23.16-22.94(\mathrm{~m}), 22.86(\mathrm{~d}, J=3.3 \mathrm{~Hz}), 14.03,13.96$, $10.49,10.43 . \mathrm{m} / \mathrm{z}$ calculated for $\mathrm{C}_{32} \mathrm{H}_{41} \mathrm{BrN}_{2} \mathrm{O}_{2} \mathrm{~S}$ : 596.21, 598.21; found: $599.25(\mathrm{M}+\mathrm{H})$. 
Step 6: 5-(4-(2,5-bis(2-ethylhexyl)-3,6-dioxo-4-(thiophen-2-yl)-2,3,5,6 tetrahydropyrrolo[3,4-c]pyrrol-1-yl)phenyl)furan-2-carbaldehyde (7)

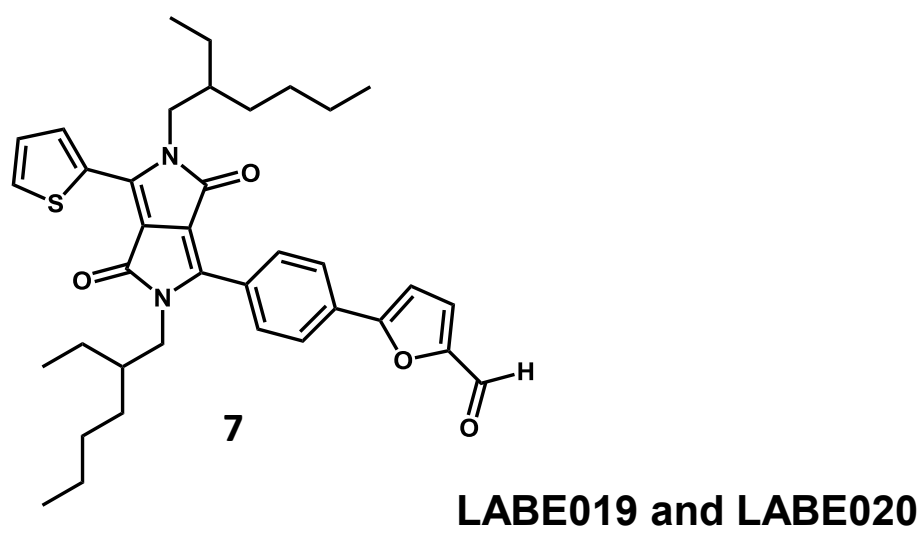

3-(4-bromophenyl)-2,5-bis(2-ethylhexyl)-6-(thiophen-2-yl)-2,5-dihydropyrrolo[3,4c]pyrrole-1,4-dione (6) (0.54 g, $0.903 \mathrm{mmol}, 1.0 \mathrm{eq})$ was dissolved in THF (27 mL). Water $(54 \mathrm{~mL})$ and sodium carbonate $(6.7 \mathrm{~g})$ were added. The reaction mixture was degassed. (5-formylfuran-2yl)boronic acid (379 mg, $2.71 \mathrm{mmol}, 3.0 \mathrm{eq})$ followed by Pd(PPh3)4 (105 mg, 0.0903mmol, $0.1 \mathrm{eq}$ ) were added and reaction was stirred at reflux $\mathrm{O} / \mathrm{N}$. After cooling to RT, layers were separated. Aqueous phase was extracted with Et2O (2 x $100 \mathrm{~mL})$. Organic layers were combined, washed with brine $(50 \mathrm{~mL})$, dried over $\mathrm{MgSO} 4$, filtered and evaporated to dryness. The crude product (7) $(0.93 \mathrm{~g}, 168 \%)$ was isolated as a red oil. This material was purified by flash-chromatography (EtOAc/hex 20:80 $\mathrm{rf}=0.22)$ to finally obtain the pure product $(7)$ $(0.51 \mathrm{~g}, 90 \%)$ as a dark red solid. $1 \mathrm{H}$ NMR $(400 \mathrm{MHz}$, Chloroform- $d$ ) $\delta 9.73(\mathrm{~s}, 1 \mathrm{H}), 8.98$ (dd, $J=3.9,1.2 \mathrm{~Hz}, 1 \mathrm{H}), 7.99$ (d, $J=8.5 \mathrm{~Hz}, 2 \mathrm{H}), 7.91$ (d, $J=8.5 \mathrm{~Hz}, 2 \mathrm{H}), 7.69$ (dd, $J=5.0$, $1.2 \mathrm{~Hz}, 1 \mathrm{H}), 7.41-7.28(\mathrm{~m}, 2 \mathrm{H}), 6.98(\mathrm{~d}, J=3.7 \mathrm{~Hz}, 1 \mathrm{H}), 4.05-3.94(\mathrm{~m}, 2 \mathrm{H}), 3.88(\mathrm{dt}, J=$ 6.7, 3.1 Hz, 2H), 1.86 (q, $J=6.4 \mathrm{~Hz}, 1 \mathrm{H}), 1.60(\mathrm{~d}, J=13.2 \mathrm{~Hz}, 1 \mathrm{H}), 1.48-1.10(\mathrm{~m}, 17 \mathrm{H})$, $0.97-0.71(\mathrm{~m}, 12 \mathrm{H})$. 13C NMR (101 MHz, Chloroform- $d$ ) $\delta 177.39,162.31,162.09$, $158.21,152.47,145.41,142.63,136.00,131.29,130.67,129.64,129.59$, 129.25 , $128.53,125.49,123.15,110.29,109.04,107.93,45.77,45.31,39.07,38.66,30.31$, $30.24,28.39,28.24,23.69,23.60,23.06,22.86,14.03,13.94,10.50,10.41 . \mathrm{m} / \mathrm{z}$ calculated for C37H44N2O4S: $612.30(100.0 \%), 613.31(40.0 \%)$; found $613.50(\mathrm{M}+\mathrm{H})$.

Step7:

(E)-3-(5-(4-(2,5-bis(2-ethylhexyl)-3,6-dioxo-4-(thiophen-2-yl)-2,3,5,6-tetrahydropyrrolo [3,4-c]pyrrol-1-yl)phenyl)furan-2-yl)-2-cyanoacrylic acid

5-(4-(2,5-bis(2-ethylhexyl)-3,6-dioxo-4-(thiophen-2-yl)-2,3,5,6-tetrahydropyrrolo[3,4c]pyrrol-1-yl)phenyl)furan-2-carbaldehyde (7) $(0.5 \mathrm{~g}, 0.82 \mathrm{mmol})$ was dissolved in THF (50 $\mathrm{mL})$. Piperidine (1.6 mL, $1.39 \mathrm{~g}, 16.3 \mathrm{mmol}, 20 \mathrm{eq})$ and 2-cyanoacetic acid (694 $\mathrm{mg}, 8.15$ mmol, 10 eq) were added to the red solution. The mixture was refluxed $7 \mathrm{~h}$ under argon atmosphere. After cooling to RT, the solvent was evaporated. The residue was taken in DCM $(100 \mathrm{~mL})$ and washed with aq. $1 \mathrm{M} \mathrm{HCl}$ solution $(50 \mathrm{~mL})$ and water $(50 \mathrm{~mL})$. Solvent was evaporated to dryness yielding the crude product $8(0.72 \mathrm{~g}, 129 \%)$ of a red-purple solidifying 
oil. This material was purified by flash chromatography (DCM100\% to DCM/EtOH 85:15). Finally $360 \mathrm{mg}(61 \%)$ of the expected compound were obtained as a red solidifying oil.

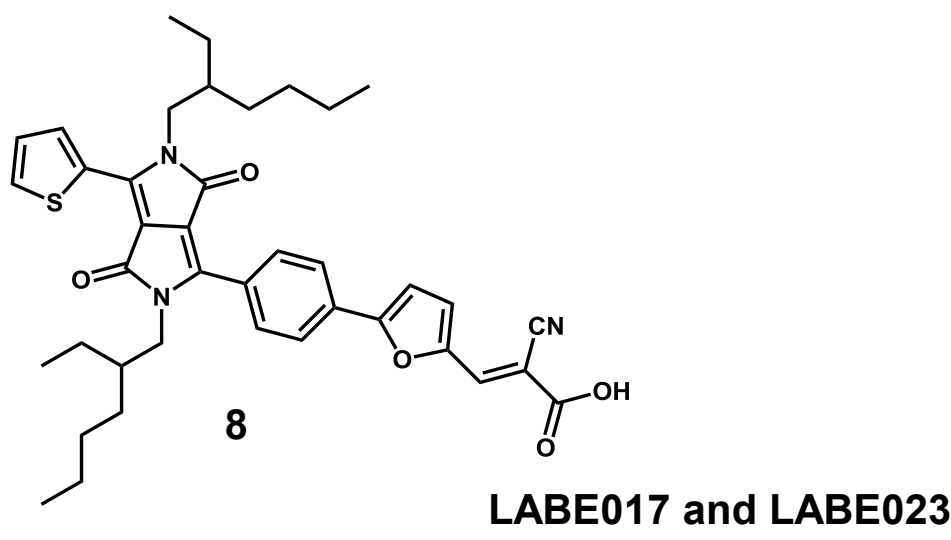

1H NMR (400 MHz, DMSO-d6) $\delta 8.84-8.78(\mathrm{~m}, 1 \mathrm{H}), 8.22-8.11(\mathrm{~m}, 1 \mathrm{H}), 8.03$ (ddd, $\mathrm{J}=$ $34.4,18.1,0.6 \mathrm{~Hz}, 4 \mathrm{H}), 7.84(\mathrm{~s}, 1 \mathrm{H}), 7.49-7.39(\mathrm{~m}, 2 \mathrm{H}), 7.32(\mathrm{~d}, J=3.7 \mathrm{~Hz}, 1 \mathrm{H}), 3.89(\mathrm{dd}, J=22.5$, $7.4 \mathrm{~Hz}, 4 \mathrm{H}), 1.72(\mathrm{dt}, J=13.3,7.0 \mathrm{~Hz}, 1 \mathrm{H}), 1.41-0.94(\mathrm{~m}, 19 \mathrm{H}), 0.83(\mathrm{qd}, J=8.0,6.8,4.6 \mathrm{~Hz}, 7 \mathrm{H})$, $0.75-0.63(\mathrm{~m}, 6 \mathrm{H}) .{ }_{13} \mathrm{C}$ NMR $(101 \mathrm{MHz}, \mathrm{DMSO}) \delta 163.82,161.77,161.62,155.44,149.85,145.89$, $141.84,135.51,134.07,133.81,131.42,129.77,129.47,129.03,128.39,124.81,121.40,119.31$, $111.34,109.34,107.46,45.39,44.74,40.68,40.63,40.47,40.42,40.26,40.21,40.00,39.79,39.59$, $39.38,38.89,38.87,38.40,38.39,30.21,30.17,30.13,30.08,28.24,28.22,28.08,23.81,23.70,22.86$, $22.85,22.60,14.22,14.13,10.76,10.72 . \mathrm{m} / \mathrm{z}$ calculated for $\mathrm{C}_{40} \mathrm{H}_{45} \mathrm{~N}_{3} \mathrm{O}_{5} \mathrm{~S}: 679.31(100.0 \%), 680.31$ (43.3\%), 681.31 (9.1\%); found $678.08(\mathrm{MH})$.

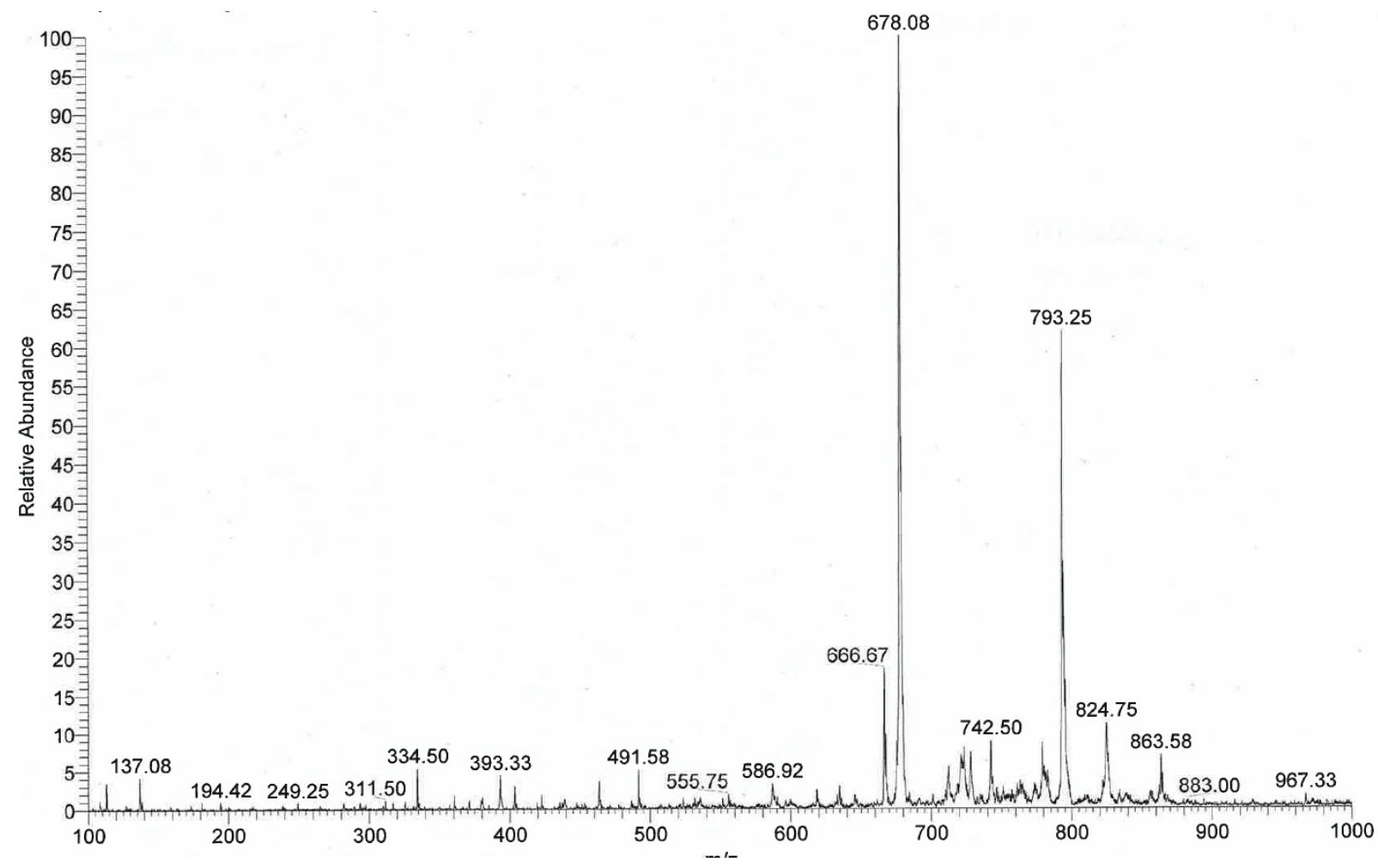

Mass spectrum of DPP_R (molecule 8) 


\section{S2. Surface concentration of sensitizer molecules}

Table S1. Calculated intermolecular distances between dye molecules adsorbed on $\mathrm{Al}_{2} \mathrm{O}_{3} . c$ is the geometric molar concentration of dyes on alumina, $\Gamma$ the molar surface density, and $d$ the average intermolecular distance between adjacent adsorbed dye molecules.

\begin{tabular}{ccccccc}
\hline & \multicolumn{3}{c}{ DPP_A } & \multicolumn{3}{c}{ DPP_R } \\
\cline { 2 - 7 } & Low & Mid & High & Low & Mid & High \\
\hline $\boldsymbol{c}\left[\boldsymbol{\mu M} / \mathbf{c m}^{2}\right]$ & 3.89 & 9.19 & 16.94 & 6.51 & 13.19 & 31.05 \\
$\boldsymbol{\Gamma}\left[\times \mathbf{1 0 - 2 5} \mathbf{~ m o l} / \mathbf{n m}^{2}\right]$ & 1.33 & 3.33 & 6.16 & 2.32 & 4.83 & 11.3 \\
$\boldsymbol{d}[\mathbf{n m}]$ & 3.54 & 2.24 & 1.64 & 2.67 & 1.86 & 1.21 \\
\hline
\end{tabular}

The average distance between neighboring DPP dyes adsorbed on the surface was derived from the dye surface density, $\Gamma$, in terms of mol per $\mathrm{nm}^{2}$ using the following calculation:

Surface area, $S$ was calculated by using $\mathrm{S}=V_{\text {alumina }}\left[\mathrm{cm}^{3}\right] \times \rho\left[\mathrm{g} / \mathrm{cm}^{3}\right] \times \mathrm{BET}_{\text {alumina }}\left[\mathrm{m}^{2} / \mathrm{g}\right]$, where $\mathrm{V}_{\text {alumina }}$ is the volume of $\mathrm{Al}_{2} \mathrm{O}_{3}$ substrate on glass $\left(4.20 \times 10^{-5} \mathrm{~cm}^{3}\right), \rho$ is the density of $\mathrm{Al}_{2} \mathrm{O}_{3}\left(3.95 \mathrm{~g} / \mathrm{cm}^{3}\right), \mathrm{BET}_{\text {alumina }}$ is the measured specific surface area of the mesoporous $\mathrm{Al}_{2} \mathrm{O}_{3}$ film obtained from Brunauer-Emmett-Teller analysis $\left(93.2269 \mathrm{~m}^{2} / \mathrm{g}\right)$. The volume of $\mathrm{Al}_{2} \mathrm{O}_{3}$ nanoparticles was obtained by calculating $V_{\text {alumina }}=$ thickness $\times$ film area $\times(1$ - porosity $)$.

Thus, in the case of 'High' DPP_A film where $9.58 \times 10^{-9}$ moles of dye were dissolved into 2 $\mathrm{mL}$ 1,8-Diazabicyclo(5.4.0)undec-7-ene (DBU), $\boldsymbol{\Gamma}$ was derived as $6.16 \times 10^{-25} \mathrm{~mol} / \mathrm{nm}^{2}$. Thus, the area covered by a single molecule on the surface was determined to $2.69 \mathrm{~nm}^{2}$. The square root of reciprocal number of the $2.69 \mathrm{~nm}^{2}$ yields a $1.64 \mathrm{~nm}$ intermolecular distance. All the calculated intermolecular distances of DPP_A and DPP_R are listed in the Table above. 


\section{S3. Kinetic parameters}

Table S2. Transient absorption kinetic parameters for DPP_A (probe at $710 \mathrm{~nm}$ ) and DPP_R (probe at $630 \mathrm{~nm})$ dissolved in 4-tert-butanol/acetonitrile mixture $(1: 1 \mathrm{v} / \mathrm{v})$ and 4-tert-butanol. The probe wavelengths were chosen, where the intermolecular interaction dynamics are the least disturbed by excited state relaxations. The relationship $\Delta A(t)=\mathrm{A}_{1} \exp \left(-t / \tau_{1}\right)+\mathrm{A}_{2} \exp (-$ $\left.t / \tau_{2}\right)+\mathrm{A}_{3} \exp \left(-t / \tau_{3}\right)$, where $\Delta A(t)$ is the transient absorption intensity, $\mathrm{A}$ the amplitude and $\tau$ the fitted decay time, is used for parameter fitting. The average time constant of the fits was calculated by using the relationship $\tau_{\mathrm{ave}}=\sum_{i=1}^{n} \mathrm{~A}_{i} \tau_{i} / \sum_{i=1}^{n} \mathrm{~A}_{i}$.

\begin{tabular}{cccccc}
\hline & \multicolumn{2}{c}{ DPP_A } & \multicolumn{2}{c}{ DPP_R } \\
& Rise $\boldsymbol{\tau}_{\text {ave }}(\mathbf{p s})$ & Decay $\boldsymbol{\tau}_{\text {ave }}(\mathbf{p s})$ & & Rise $\boldsymbol{\tau}_{\text {ave }}(\mathbf{p s})$ & Decay $\boldsymbol{\tau}_{\text {ave }}(\mathbf{p s})$ \\
\hline $\mathbf{1 5} \boldsymbol{\mu M}$ & - & - & $\mathbf{2 4} \boldsymbol{\mu M}$ & - & 878 \\
$\mathbf{1 3 0} \boldsymbol{\mu M}$ & 2.3 & 25 & $\mathbf{1 4 0} \boldsymbol{\mu M}$ & 80 & 580 \\
\hline
\end{tabular}


S4. Steady-state absorption spectra
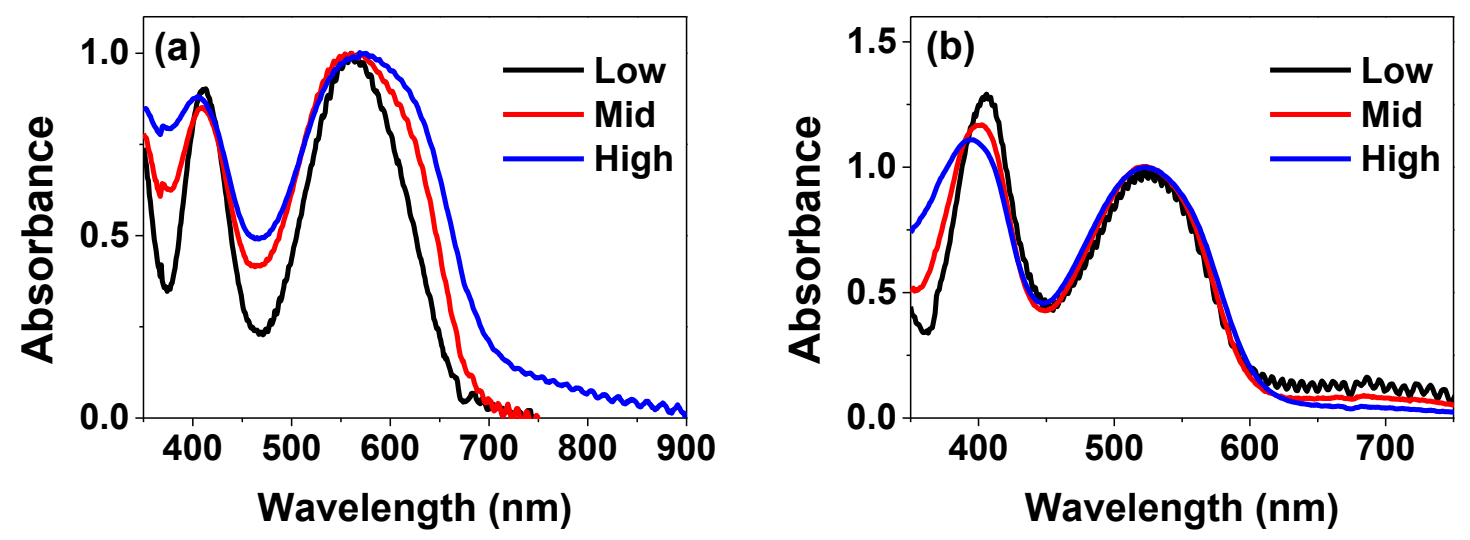

Figure S1. Normalized steady-state absorption spectra of DPP_A (a) and $\mathbf{D P P} \mathbf{R}$ (b) in film with different dye concentrations. "low" (dye/CDCA =1:100), "mid" (dye/CDCA = 1:50), and "high" (dye/CDCA = 1:0) films were used. 

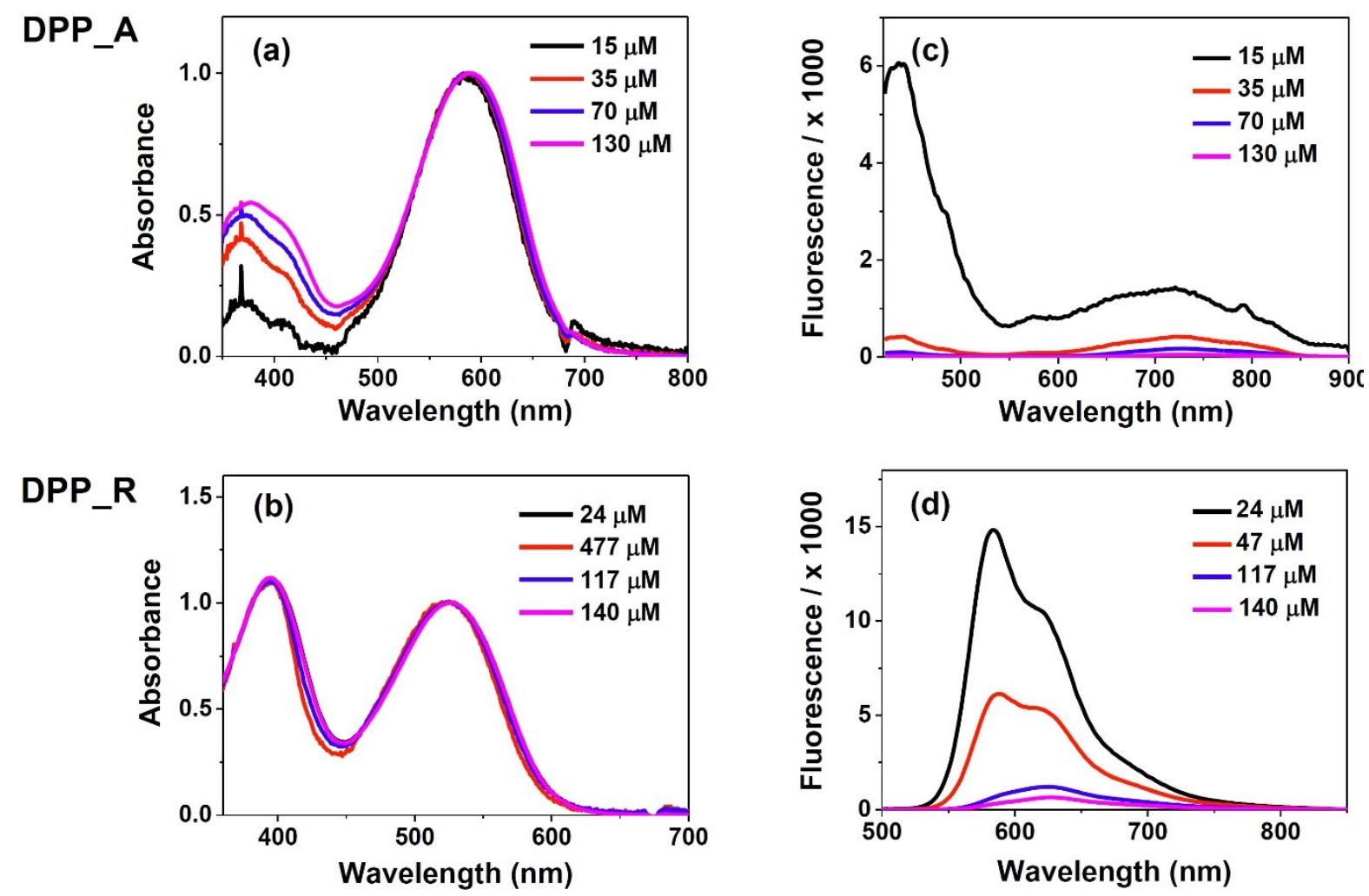

Figure S2. Normalized steady-state absorption spectra of DPP_A (a) and DPP_R (b) in solution with different dye concentrations. The fluorescence spectra of $\mathbf{D P P} \mathbf{A}_{\mathbf{A}}$ (c) and DPP_R (d) were normalized by fraction of absorbed photons at excitation wavelength $(390 \overline{\mathrm{nm}})$.

Table S3. Intensity ratios of high energy band $\left(I_{\mathrm{H}}\right)$ to low energy band $\left(I_{\mathrm{L}}\right)$ measured from absorption spectra of $\mathbf{D P P} \_\mathbf{A}, \mathbf{D P P} \mathbf{R}$ in solution. The intensity ratio obtained from spectra measured on $\mathrm{Al}_{2} \mathrm{O}_{3}$ are shown for comparison.

\begin{tabular}{cccccccc}
\hline & \multicolumn{3}{c}{ DPP_A $\left(I_{\mathbf{H}} / I_{\mathbf{L}}\right)$} & \multicolumn{3}{c}{ DPP_R $\left(I_{\mathbf{H}} / I_{\mathbf{L}}\right)$} \\
\cline { 2 - 8 } & Solution & & on $\mathbf{A l}_{\mathbf{2}} \mathbf{O}_{\mathbf{3}}$ & & Solution & & on $\mathrm{Al}_{2} \mathbf{O}_{\mathbf{3}}$ \\
\hline $\mathbf{1 5} \boldsymbol{\mu M}$ & 0.20 & Low & 0.88 & $\mathbf{2 4} \boldsymbol{\mu M}$ & 1.12 & Low & 1.28 \\
$\mathbf{3 5} \boldsymbol{\mu M}$ & 0.42 & Mid & 0.85 & $\mathbf{4 7} \boldsymbol{\mu M}$ & 1.10 & Mid & 1.17 \\
$\mathbf{7 0} \boldsymbol{\mu M}$ & 0.50 & High & 0.90 & $\mathbf{1 1 7} \boldsymbol{\mu M}$ & 1.11 & High & 1.11 \\
$\mathbf{1 3 0} \boldsymbol{\mu M}$ & 0.54 & & & $\mathbf{1 4 0} \boldsymbol{\mu M}$ & 1.12 & & \\
\hline
\end{tabular}




\section{S5. Transient absorption spectra}

(a) DPP_A

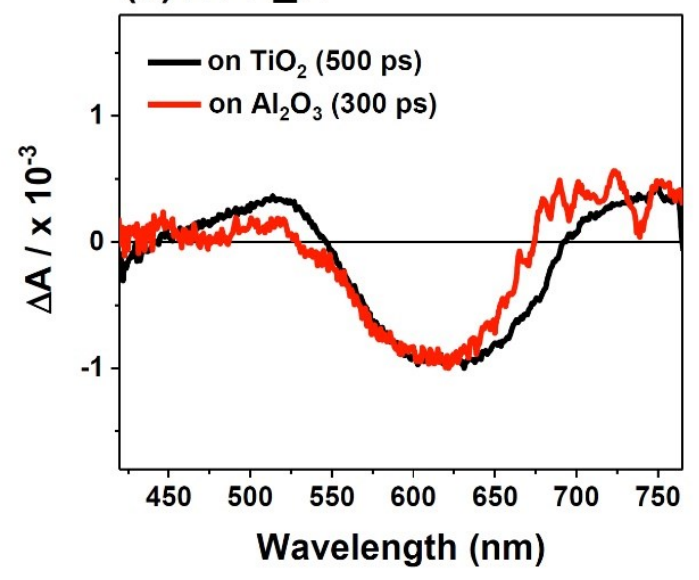

(b) DPP_R

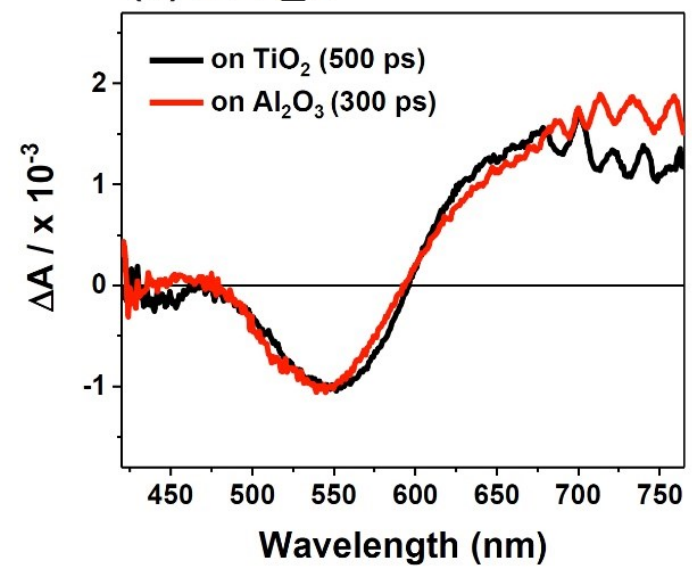

Figure S3. TA spectra of DPP_A (a) and DPP_R (b) on $\mathrm{Al}_{2} \mathrm{O}_{3}$ without co-adsorbant, CDCA, and those on $\mathrm{TiO}_{2}$. Time delays at $500 \mathrm{ps}$ on $\mathrm{TiO}_{2}$ and at 300 ps on $\mathrm{Al}_{2} \mathrm{O}_{3}$ were selected. All the spectra were excited at $390 \mathrm{~nm}$ with $30 \mu \mathrm{J} / \mathrm{cm}^{2}$ energy fluence, and were normalized by the $\Delta A$ value at maximum ground state bleaching (GSB). 